\title{
Et erubuit. Simbolismo del color y de la materia en los epigramas neolatinos
}

\author{
Marcos Ruiz SÁNCHEZ \\ Universidad de Murcia \\ marcosr@um.es
}

Recibido: 6 de mayo de 2013

Aceptado: 26 de mayo de 2013

\section{RESUMEN}

La expresión uidit et erubuit con que concluye el famoso epigrama de R. Crashaw sobre el milagro de la conversión del agua en vino en las bodas de Caná responde a una clase de cierre poético muy común en la poesía neolatina. El examen de algunos ejemplos muestra que este tipo de conclusión está ligado a una serie de contextos relacionados a su vez con determinados motivos y símbolos. No hay que pensar tanto en la influencia directa de unos textos sobre otros como en la existencia de un tipo de sensibilidad poética propia de la época.

Palabras clave: R. Crashaw. Poesía neolatina. Epigrama. Poesía religiosa. Cierre poético. Emblemas.

Ruiz SÁnchez, M., «Et erubuit. Simbolismo del color y de la materia en los epigramas neolatinos», Cuad. Fil. Clás. Estud. Lat. 33.1 (2013) 73-103.

\section{Et erubuit. Color and Matter Symbolism in Neo-Latin Epigrams}

\begin{abstract}
The expression uidit et erubuit at the end of R. Crashaw's famous epigram on the miracle of turning water into wine at the wedding feast in Cana responds to a type of poetic closure that is very common in neo-Latin poetry. Examination of a few examples shows that this type of ending is linked to a series of contexts related in turn to certain motifs and symbols. One must not think so much about the direct influence of some texts on others as about the existence of a kind of poetic sensitivity in keeping with the time.

Keywords: R. Crashaw. Neo-Latin poetry. Epigram. Religious poetry. Poetic closure. Emblems.

Ruiz SÁnchez, M., «Et erubuit. Color and Matter Symbolism in Neo-Latin Epigrams», Cuad. Fil. Clás. Estud. Lat. 33.1 (2013) 73-103.

Sumario 1. Vidit et erubuit. 2. Ficción y concepto. 3. El rubor de la rosa. 4. Actualizaciones del tema de la rosa. 5. Sobrepujamiento y metamorfosis. 6. La personificación del instrumento del crimen y el martirio religioso. 7. Ambivalencias simbólicas. 8. La rosa y el coral. 9.1. La transubstanciación del agua en vino. 9.2. El desarrollo del texto. 9.3. El epigrama en el contexto de la poesía de Crashaw. 10. Conclusiones: el epigrama de Crashaw y la poesía neolatina. 11. Referencias bibliográficas.
\end{abstract}




\section{VIDIT ET ERVBVIT}

Nympha pudica Deum uidit, et erubuit: «La ninfa ha visto a Dios y, llena de pudor, ha enrojecido». Este famosísimo verso es el pentámetro final de un epigrama latino sobre el milagro de las bodas de Caná, obra de Richard Crashaw (1612-1649), autor de una importante obra poética en inglés y en latín. El verso acabó adquiriendo vida propia, independizándose del poema del que formaba parte y de su propio autor; fue atribuido a Dryden y citado con muy diversas variantes. Se produjo así un proceso de descontextualización en el que el verso se vio privado de su contexto autorial, histórico, ideológico, literario e incluso textual.

Sin embargo, el poema en cuestión tiene numerosos paralelos en la poesía religiosa, especialmente en el epigrama neolatino de la época. La propia cláusula final del texto, uidit et erubuit, corresponde, por otra parte, a un tipo de cierre poético muy común en esta poesía, que se aplica aparentemente en una gran cantidad de contextos $^{1}$. El propósito de estas páginas es precisamente examinar la naturaleza y los usos de este tipo de cierre en la poesía neolatina.

\section{FICCIÓN Y CONCEPTO}

Una clase de contextos en que suele ser frecuente este tipo de cierre podemos verlo en textos, como este epigrama en elogio de una estatua de B. Cellini (Tassi 1829, p.484):

Hunc Natura parens spectabat Persea, et una

Contemplabatur Gorgona et Andromeden:

Et summe admirans, et laudans singula: 'uicit Me manus Artificis', dixit, et erubuit.

«La Madre Naturaleza contemplaba este Perseo y con él a la Górgona y Andrómeda. Y admirando y elogiando sumamente cada uno de los detalles, "Me ha vencido", dijo, "la mano del artista", y se ruborizó».

Se trata de una variación del tópico del sobrepujamiento. La ficción sirve de vehículo al concepto basado en la comparación. Una divinidad de la mitología clásica des-

\footnotetext{
${ }^{1}$ El cliché consiste en el uso como cierre del texto de la expresión et erubuit -o giros equivalentes-, precedida con frecuencia de una forma verbal como uidit, sensit o dixit. Análogo a este tipo de cliché es también el que concluye con la transformación del sujeto en piedra y que puede terminar formalmente con un obriguit, equivalente métricamente a erubuit. Sensit et erubuit es, por otra parte, una juntura que se encuentra ya -pero sin carácter conclusivo- en Ov.Met.10.293. Ovidio utiliza la frase para referirse al proceso de animación de la estatua de Pigmalión. Cuando el artista, enamorado de su obra, la abraza, ésta cobra vida: «la joven sintió que se la estaba besando y enrojeció». La expresión uidit et erubuit se encuentra también usada para expresar el enamoramiento súbito, como puede verse en el siguiente poema de J. Verzosa (De se et Charina, en Clariorum Aragonensium Monumenta, 49-50): Aestus erat cum Daphnaeis sub frondibus aestum / uitabat flanas fusa Charina comas. / Lenia subiecti captabat murmura fontis, / atque sua in uitreis ora uidebat aquis. / Tunc illo me duxit Amor: prior ipse Charinam / ut uidi, erubui; uidit, et erubuit.
} 
cubre la existencia de un objeto o persona que provoca su admiración. El objeto del elogio estará estrechamente relacionado con la esfera de acción que representa la divinidad en cuestión, o puede incluso ser un doble de la misma, como ocurre con la dama del poeta en relación con Venus, el héroe militar con respecto a Marte, etc. El texto concluye habitualmente con el discurso del personaje que sirve para explicitar el concepto; la agudeza final reproduce así en abismo el concepto subyacente a la ficción, reiterando la comparación entre los dos personajes, explicando la semejanza y la diferencia, subrayando la superioridad del personaje actual, etc. El motivo del rubor, confesión de vergüenza ante la superioridad del elogiado, actúa como un tipo de cierre alternativo, que puede añadirse al discurso final del personaje mítico, o substituirlo ${ }^{2}$.

Una variante del mismo tipo de ficción se produce cuando la propia divinidad confunde al personaje humano actual o incluso una estatua con algún otro personaje mítico. Al reconocer su error, enrojece de vergüenza. Por ejemplo, en el siguiente epigrama Marte confunde una estatua de Venus dormida con la propia Venus ${ }^{3}$ :

\section{Mars Venerem ut uidit carpentem in gramine somnos, \\ Festinat lateri iungere posse latus: \\ Accubat, at saxo ut sensit se uana dedisse \\ Oscula, delusus risit, et erubuit.}

«Al ver Marte a Venus disfrutando del sueño sobre la hierba, se apresura a aprovechar la ocasión de unir su costado al suyo; se recuesta junto a ella, pero, al sentir que eran vanos sus besos, al verse engañado, se echó a reír y enrojeció».

En otras ocasiones es la propia dama del poeta la que es confundida por la divinidad, como ocurre, por ejemplo, en este epigrama de Fabio Segni, De Neara ${ }^{4}$.

\footnotetext{
${ }^{2}$ Un ejemplo parecido es el siguiente epigrama de F. Pacheco (Pozuelo Calero 1994, p.376), en el que aparece una frase similar (risit et erubuit):

Lautitias, Petre docte, tuas miratus Apollo Luculli sordes risit et erubuit.

Transtulit ergo sacras melior ad fercula Musas

Et Veneres secum transtulit et Charites;

Atque ait: iste foret, Cicero, tibi lautior hospes,

Nec magis ulla tuae digna popina gulae est.

«Maravillado Apolo ante la esplendidez de tu cena, docto Pedro, las miserias de Lúculo le han hecho reír y sonrojarse. Ha trasladado, pues, las sacras Musas a tus platos, que resultan preferibles, y se ha traído consigo los Deleites y la Gracias; y proclama: “Éste sería, Cicerón, tu anfitrión más espléndido, porque no hay mesa en el mundo más digna de tu paladar"».
}

El motivo se aplica frecuentemente a la belleza femenina. Baste citar este ejemplo de G. Rollenhagen, Aurora et Paeta (1606, p.21): Nuper purpureos agitans Matuta caballos / Viderat e summo te, mea Paeta, polo. / Scilicet o Virgo mihi nunc mea forma pudori est, / Cedo tibi mannos dixit: et erubuit: «Al verte hace poco Aurora desde lo alto del cielo, mientras guiaba sus purpúreos caballos, dijo: "Ciertamente, doncella, mi propia belleza me avergüenza ahora; te cedo mis caballos". Y se sonrojó».

${ }^{3}$ Obra de F. Franchinus. Cf. J. Gruter 1608, I, p.1141.

${ }^{4}$ Carmina quinque Hetruscorum poetarum, 1562, p.111, Carmina Illustrium Poetarum Italorum, IX, 1722, p.25. Una versión inglesa de este texto puede leerse en F.P. Barnard (1922, p.21): «Cupid, his winged way 


\begin{abstract}
Aliger occurrit dum forte Cupido Neaerae, Esse ratus Venerem, quo mea mater? ait, Utque fuit puero gratissimus agnitus error, Obstupuit deinceps, erubuitque simul.
\end{abstract}

«Al encontrarse casualmente el alado Cupido con Neera, le dice, creyendo que de Venus se trataba: "A dónde vas, madre mía". Y cuando el niño dios reconoció su gratísimo error, quedó luego estupefacto y al tiempo se ruborizó » ${ }^{5}$.

La dama puede reaccionar en tales ocasiones de forma airada, lo que marca la diferencia entre ella y el personaje mítico con el que es comparado. Cupido confunde, por ejemplo, a Celia con Venus en el siguiente epigrama de G. Angeriano (c. 1480-1535), De Caelia et Cupidine (1582, fol. 20):

\title{
Flebat Amor, matremque suam quaerebat: at ipsa Ut uisa est uultu Cloelia pulchra suo. \\ Ipsam appellat Amor matrem: sed Caelia toruo Lumine ait, non sum Mater, Amor rubuit.
}

«Lloraba Amor y buscaba a su madre; al ver el hermoso rostro de Celia, la llama madre. Pero Celia mirándolo con torvos ojos, le contesta: "No soy yo tu madre". Y Amor se sonrojó» ${ }^{6}$.

pursuing, / Upon Neaera chanced. / He thought her Venus. 'What's a-doing, / Mother? ' cried he. Then, tranced, / His error saw at second viewing, / E'en blushing as he glanced».

${ }^{5}$ En el siguiente poema de G. Rollenhagen (1606, p.59), se mezclan distintos tópicos de la poesía amorosa uniendo la equivocación del amor ciego, con la queja del enamorado, tradicional desde el epigrama griego: Coecus Amor positis spectans me lumine uittis / lustrabat telis saucia corda suis. / Ah ignosce, precor, fixit meus arcus amicum, / hostem dum petii, dixit et ingemuit: «El ciego amor, observándome con sus propios ojos, tras dejar sus vendas, contemplaba mi corazón herido por sus flechas: ‘ $¡ A y$ !, perdóname, te lo ruego: mi arco te ha traspasado, a pesar de ser amigo, mientras creí atacar a un enemigo’. Así dijo, y se sonrojó».

${ }^{6}$ El mismo motivo, reducido a su mínima expresión puede verse en un epigrama de Germain de Brie (G. Brixius), en Delitiae C. Poetarum Gallorum I (Gruter 1609, p.765): Forte tuam uidit Venerem, Francisce, Cupido: / Moxque ait, o salue mater; et erubuit. Angeriano ha desarrollado el mismo motivo en una serie de composiciones en su Erotopaegnion. Así, en De Venere et Cupidine (1582, fol.7) Cupido abrasa con su antorcha el pecho de Venus y, al quejarse la diosa, se disculpa afirmando que creía que era Celia (vv.6-10): Palluit audito matris clamore Cupido; / palluit, utque silex obriguere comae. / Flens tandem dixit, non est tibi Caelia dispar; / hanc uolui, non te, parce, ferire deam («Palideció Cupido al oír el clamor de su madre; palideció y sus cabellos se pusieron rígidos como si fueran de piedra. Llorando, al fin dijo: "no es inferior a ti Celia; es a ella, no a ti, diosa, a quien quise herir"»). En otro poema de Angeriano (De Caelia, et Amore, 1582, f.2), se desarrolla el motivo inverso. Cupido se equivoca y dirige sus flechas contra Celia creyendo que es la propia Venus (vv.612): Cur ita trudor? ait deus; admiratur; at illa / illa inquit, non sum Caelia nota tibi? / Ut pede qui pressit colubrum, post horret, abitque. / Sic miser audito hoc nomine fugit Amor. / Et fugiens dixit, fugienti parce, parentem / credideram, non te. Tu mihi uisa parens (“¿Por qué de este modo se me rechaza?” Dijo el dios, sorprendido. Y ella respondió: “¿Es que no me conoces? Soy Celia”. Como quien ha pisado una serpiente y queda horrorizado y sale huyendo, así al oír tal nombre huyó el desdichado Amor. Y, mientras huía, dijo: "Perdona a quien de ti huye; creía que eras mi madre, no tú. Te tomé por ella"»). Totalmente similar es un soneto de F. de Figueroa (1989, p.146): «Pasaba Amor en despoblado un dia, / sus flechas de oro a punto, su arco armado; / un corro vio de ninfas apartado / en un pradillo verde que alli había. / Venus, su madre, estrellas descubría, / su rostro alegre, grave, mesurado; / vióla y turbóse Amor, y así turbado / arrójale una jara que traía. / “'Ay hijo, dijo Venus, que me heriste! / ¿En mi empleas tu arco?, ¿en mí tus tiros? / ¿Qué desafuero, qué descortesía!” / Vio el yerro Amor y, turbadillo y triste: / "No quise, dijo, a fe, no quise heriros, / pensé que érades Fili, madre mía"》". 


\section{EL RUBOR DE LA ROSA}

El tema de la metamorfosis de la rosa fue objeto de numerosos desarrollos en la poesía neolatina. He aquí el texto de dos epigramas paralelos sobre este tema. La relación entre ambos es evidente, no sólo por la semejanza temática, sino por las repeticiones léxicas que los enlazan. El primero es obra de Fausto Sabeo (1556, p.4):

Carpit odoratis spatians dum Cypria ab hortis

Roscidulas primo sub oriente rosas,

Sancta cruentarunt uepres sua bracchia acuti,

Palluit inspecto sanguine pulcra Venus.

Erubuere deam flores laesisse cruenti,

Constat adhuc facti poenituisse rosas.

«Mientras Venus paseando coge de los perfumados jardines las rosas cubiertas de rocío al rayar el alba, las agudas espinas ensangrentaron sus sagrados brazos. Palideció la hermosa Venus al ver la sangre y las flores, ensangrentadas, se sonrojaron por haber hecho daño a la diosa. Desde entonces - es sabido- las rosas se arrepienten de su crimen».

El segundo fue escrito por Jean Lernout (1614, p. 386):

Dum septis Cytherea rosas legit aurea in hortis,

Quas iuueni in sertum plecteret Assyrio;

Spinarum imprudens distrinxit acumine dextram:

Nec mora: conspectu sanguinis icta sui,

Palluit: utque deam flores sensere pauentem;

Ex illo semper erubuere rosae.

«Mientras la áurea Citerea coge en sus cercados jardines rosas, para trenzar con ellas una corona para el joven sirio, una espina atormentó imprudente su diestra con su aguijón; herida, palideció al punto al ver la sangre y, al darse cuenta las flores del pavor de la diosa, se sonrojaron y desde entonces conservan su rubor».

Estos dos poemas suponen un desarrollo conceptual del tema mítico del nacimiento de la rosa ${ }^{7}$. Pero en las versiones normales de esta historia, las que siguen la versión de Aftonio, difundida en el Renacimiento por Poliziano, que liga la metamorfosis de la rosa a los amores de Venus y Adonis y los celos de Marte, Venus se hiere en el pie, mientras que en los dos poemas neolatinos citados esta circunstancia mitológica con-

\footnotetext{
${ }^{7}$ Esta variación del tema tradicional puede considerarse ya implícita en la latinidad tardía, en un epigrama de Draconcio (De origine rosarum, vv.1-6): Alma Venus quondam dum Martis uitat amores / et pedibus nudis florea prata premit, / sacrilega placidas irrepsit spina per herbas / et tenero plantas uulnere mox lacerat. / Funditur inde cruor; uestitur spina rubore; / quae scelus admisit, munus odoris habet («Mientras la madre Venus evita en otro tiempo los amores de Marte y pisa con sus pies desnudos los floridos prados, una espina se arrastró sacrílega por entre las inofensivas hierbas y laceró con tierna herida sus plantas. Brota la sangre y la espina se viste de rubor; admite su crimen y obtiene como regalo su perfume»).
} 
creta ha sido substituida por un cuadro idílico en que Venus está recogiendo flores y se hiere en la mano (Poliziano 1602, 23-25). En el texto de Lernout hay, con todo, una alusión a Adonis y la referencia a los jardines en el texto de Sabeo puede implicar la misma conexión, pero la circunstancia no es la misma.

El desarrollo conceptual de estos dos epigramas, meras variaciones del mismo tema, se basa en la intencionada ambigüedad de los términos rubere y rubore, que, por una parte, designan metafóricamente el hecho de que las rosas se cubren de sangre, y, por otra, el rubor provocado por la vergüenza. La metáfora es coherente con el contexto mitológico. Dentro del universo del mito es posible entender la transformación como fruto del poder milagroso de la divinidad, al igual que otras metamorfosis que relacionan en la mitología las flores con la sangre, o bien como la simpatía de los elementos naturales: la flor, culpable involuntaria de la herida de la diosa, se ruboriza por su culpa.

Este tipo de manierismo conceptual aprovecha la ambigüedad propia del lenguaje figurado. Cualquier enunciado que viola la exigencia conversacional de veracidad, afirmando algo aparentemente falso, como ocurre con la metáfora, puede siempre interpretarse como un enunciado que implica un universo especial -mitológico, mágico o religioso-, que se ajusta a un modelo de mundo distinto del que aceptamos como normal, o bien como lenguaje figurado, es decir, como una forma de expresar algo que de otro modo no podría ser expresado, o, finalmente, como un error de percepción, que, por otra parte, podría reflejar una realidad más profunda.

La poesía manierista, como hemos visto en los ejemplos anteriores, nos presenta con frecuencia pequeños cuadros mitológicos, falsamente narrativos, en los que la ficción es simplemente el equivalente de un concepto. La equiparación entre la dama y la diosa en los ejemplos anteriores, se presenta precisamente como un error de percepción de la divinidad equivocada y la identificación no se llega a producir. En otros casos la comparación entre los dos términos se expresa a través del tema de la rivalidad, la diosa se siente ofendida y el rubor es una confesión tácita de inferioridad. La metamorfosis puede darse también dentro de dicho tipo de ficción. El dios equivocado puede convertirse en estatua; la diosa puede provocar la metamorfosis por contagio o por deseo de transformar el objeto de sus celos.

En estos casos la ficción mitológica forma parte del concepto del poema. En cambio, en los poemas neolatinos sobre el nacimiento de la rosa la mitología juega un doble papel. Por una parte, constituye el argumento de la historia, que debemos aceptar como real para disfrutar del poema, mientras que, por otra, actúa como código cultural que permite explicar la transformación como una personificación de la flor; dicha transformación resulta ambigua, pues podría entenderse de forma natural (la sangre que cubre las flores) o como un prodigio (cambio de color de las flores por el poder divino de la diosa).

En los poemas de Sabeo y Lernout sobre la rosa el texto se nos presenta como uniformemente narrativo. Cada uno de los tres dísticos que los forman corresponden a un momento temporal: el primero presenta el escenario, en el segundo la herida actúa como desencadenante de la transformación y en el tercero, finalmente, se produce la reacción de las rosas ante la culpa. Existe, sin embargo, en estos dos textos una dife- 
rencia entre los dos primeros dísticos y el tercero. La información que puede deducirse del texto desde el punto de vista meramente referencial está de hecho prácticamente completa en los dos primeros. La diosa ha sido herida y su sangre ha manchado las rosas. Sólo se añade la noticia de que dicho color permanecerá para siempre unido a la rosa. De ahí que el tercer dístico deba entenderse preferentemente desde el punto de vista onomasiológico y figurado. Por lo demás, la diferencia entre las secciones está atenuada, pues el contraste entre la palidez de la diosa (palluit: primera palabra del verso 3 de Sabeo y del 4 de Lernout) y el rubor de las flores atenúa la diferencia. De este modo, el final de los textos sobre la transformación de la rosa ofrece una ambigüedad pragmática, pues el lector debe elegir entre interpretar el texto como una auténtica narración de carácter mitológico, o entender que no se trata de un auténtico relato, sino de una ficción conceptual: la transfuncionalización narrativa de un concepto.

\section{ACTUALIZACIONES DEL TEMA DE LA ROSA}

En el siguiente epigrama de F. Segni encontramos una especie de actualización del motivo de la metamorfosis de la rosa $(\text { De Cynthia })^{8}$ :

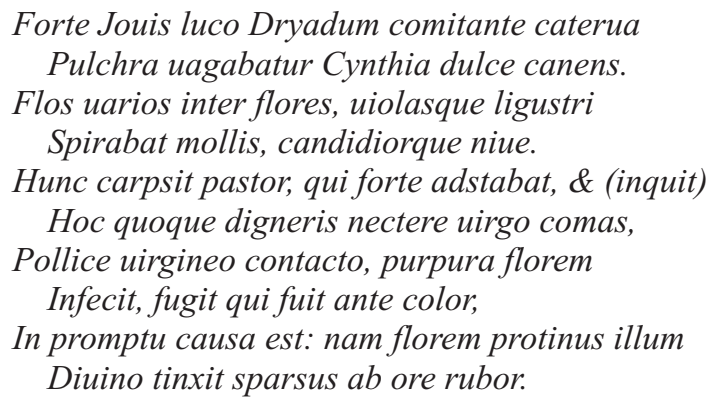

«Mientras Cintia, acompañada de una cohorte de ninfas, paseaba casualmente por el bosque de Júpiter cantando dulcemente, una flor de alheña entre violetas y otras flores exhalaba su olor, dulce y más blanca que la nieve. Un pastor, que casualmente allí estaba, la cogió y dijo: "Dígnate, doncella, adornar con esta flor tus cabellos". Al ser tocada por la mano virginal, se tiñó de púrpura la flor y el color que antes tenía huyó de ella. La causa es evidente: el rubor esparcido del divino rostro se contagió a la flor».

La flor actúa en este caso como substituto simbólico de la propia diosa.

Una versión a lo divino del tema del origen de la rosa se encuentra en el siguiente poema del jesuita T. Galluzzi (1574-1649) ${ }^{9}$ :

\footnotetext{
${ }^{8}$ Carmina quinque Hetruscorum poetarum, 1562, p.108, Carmina Illustrium Poetarum Italorum, IX, 1722, p.23.

${ }^{9}$ Galluzzi 1616, p.473; 1619, p.400.
} 
Ante Patris primi noxam sine sentibus ullis

Esse rosas genitas, candidulasque ferunt.

Ast ubi siderei uiolauit iussa Tonantis,

Sentibus armatas erubuisse rosas.

Spina est culpa nocens, rubor est genitabile crimen:

Quae totum lacerant inficiuntque genus.

Res mira: existit patrio sine crimine Virgo,

Candidaque et uernans, et sine sente rosa.

Integros iterum mores sperate: redibunt

Innocua, et primi tempora cana Patris.

«Cuentan que las rosas fueron engendradas sin espinas y que eran blancas antes del pecado de nuestro primer padre. Pero, cuando Adán violó los mandatos de nuestro padre celestial, armadas de espinas enrojecieron las rosas. La espina representa la culpa dañina y el rubor el pecado original: ambos perjudican y tiñen nuestro entero linaje. Auténtico milagro: hubo una Virgen libre de pecado, una rosa cándida y primaveral y sin espinas. Esperad por ello que la integridad moral pueda existir de nuevo. Volverán los tiempos inocentes y cándidos de nuestro padre primero».

El mito, asociado con Venus, se vincula ahora al tema del pecado original y la Virgen María hereda parte de los atributos de la diosa Venus. La Virgen, libre de pecado original, rosa blanca y sin espinas se opone a la rosa roja del pecado y contrasta implícitamente con Eva, antifigura de María.

Un nuevo uso del motivo podemos encontrarlo en un poema de Juan Interián de Ayala $(1656-1730)^{10}$ :

Quid te spinetis, iuuenis sanctissime, uoluis,

Lancinat \& tenerum sentis acerba latus?

Iam scio: perstrinxit purum mala flamma cruorem;

Hoc nisi quam fuso, perdere posse, negas.

Vicisti: extincta est flamma haec, quo canduit igne;

Seque uidens uictam, protinus erubuit.

Quam bene! Nam mollis spinis dea Cypris abhorret.

Et fugit armatos cautior illa rubos.

«¿Por qué, joven santísimo, te revuelcas entre los zarzales y las acerbas espinas desgarran tu costado? Ya lo sé: se apoderó de tu sangre una llama dañina, de la que no podías deshacerte sino derramándola. Venciste: apagada está la llama con el fuego con el que ardió. Viéndose vencida, al punto enrojeció. ¡Bien está! Pues la divina Venus en su blandura aborrece las espinas y huye precavida de las armadas zarzas».

Una vez más se evoca el mito de Venus herida por las espinas. El rubor de la llama de la lujuria, se entiende naturalmente como alusión al color rojo de la llama, pero también al rubor de la vergüenza del santo y a la sangre que cubre su cuerpo desnudo por obra de las zarzas. Las espinas tienen aquí el valor simbólico de protección de la castidad.

${ }^{10}$ Interián de Ayala 1729, p.117. Este mismo poema aparece citado en el Pictor Christianus eruditus (1730, p.16; 1782, I, p.40), obra del mismo clérigo y académico del XVIII. 


\title{
5. SOBREPUJAMIENTO Y METAMORFOSIS
}

En los ejemplos citados anteriormente en que este tipo de cierre poético iba unido al tópico del sobrepujamiento, la ficción era, como hemos visto, mero vehículo de un concepto basado en la comparación. No había, sin embargo, metamorfosis del objeto. Pero tal posibilidad no está excluida ${ }^{11}$. Podemos, de este modo, encontrar en la poesía del XVII textos muy artificiosos, que combinan los dos tipos de contexto que hemos considerado hasta ahora. Citaremos tan sólo dos ejemplos. En el siguiente poema de Carlo d'Aquino (De Rosarum fasciculo ex cera), moldeado una vez más sobre el tema de la metamorfosis de la rosa, encontramos de nuevo la divinidad equivocada (1701, pp.128-129):

\author{
Mellea turba, rosis quam nutrit sedula Chlor: \\ Instituit Dominae dona referre suae. \\ Assimilant ceris Cythereia germina; reddunt \\ Floribus succos, quos rapuere prius. \\ Vera putes: unus color est obscurior illis; \\ Eductis ceris qualis inesse solet. \\ Haec igitur Florae ueloces munuscula mittunt; \\ Quae gestat niuea casta Melissa manu. \\ Germina Diua suo reputans e cespite nata, \\ Naribus admouit protinus illa suis: \\ Decepta erubuit: quod solum defuit illis, \\ Numinis uultu tunc rubuere rosae.
}

«La turba melífera que nutre diligente Flora decidió devolver a su dueña sus dones. Modelan en cera un manojo de las flores de Citerea. Devuelven a las flores los jugos que antes les arrebataron. Creerías que eran auténticas: tan sólo su color es más oscuro, como suele ser el de los productos de cera. Así pues, veloces envían a Flora esta pequeña ofrenda, que porta en su blanca mano la casta Melisa. La diosa creyendo que las flores eran genuinos productos del reino vegetal las aproximó al punto a su rostro para olerlas y, al comprender su error, se sonrojó. Las rosas entonces adquirieron del rostro de la diosa su color rojo, única cosa que les faltaba».

\footnotetext{
${ }^{11}$ Cupido, tras reconocer su error, puede decidir, por ejemplo, quedarse junto a la amada y desde entonces habitará en sus ojos, desde donde arroja los dardos que hieren a sus víctimas. Venus, que ha confundido al rey con el propio Marte, se quedará junto a él convertida en estatua, etc. En una variante de este tipo de desarrollo la divinidad, llevada de la rivalidad, trata de inferir un daño al objeto de sus celos, sin conseguir menoscabarlo, pues su acción lejos de disminuir el atractivo lo aumenta. Así, J. Posthius (1595, p.232) ha dedicado dos epigramas a variar el tema del lunar de la dama. En uno de ellos (Cum natura tuos, Virgo pulcherrima, uultus...) Venus celosa trata de dañar la belleza de la joven, pero sólo consigue incrementarla. En el otro (Obuius ut nuper Lepidinae uenerat ille...) Cupido besa a la dama creyendo que se trata de Venus, pero al contemplar el lunar comprende su error y se disculpa. Una elaboradísima variante de este tipo puede verse en un poema de F. Panigarola (Quam moriens nondum perfectam liquit Apelles..., Carmina Illustrium Poetarum Italorum, VII, 1720, p.68): Júpiter decide concluir la imagen de Apeles que éste había dejado inacabada al morir y hace que cobre vida, convertida en mujer. La primera mitad del poema concluye con la reacción celosa de Venus y el tipo de cierre que nos ocupa: Tunc primum forma uinci Citherea decora, / pictam a pictura uidit, et erubuit (vv.7-8). La diosa decide entonces convertirla a su vez de mujer en varón, pero no consigue disminuir su belleza, sino, al contrario, incrementarla.
} 
Pero en este caso el rubor de la diosa, fruto de su confusión, contagia, en clara evocación del tema del origen de la rosa, a las propias flores artificiales, culpables del error de la diosa y que adquieren así el color que les faltaba.

En el siguiente texto del poeta inglés del siglo XVII Robert Herrick, es, en cambio, la rivalidad la que produce el enrojecimiento de las rosas, renovando una vez más el antiguo prodigio (1869, p.111, How Roses came red $)^{12}$ :

Roses at first were white, Till they co'd not agree,

Whether my Sapho's breast, Or they more white sho'd be.

But being vanquisht quite, A blush their cheeks bespred;

Since which, beleeve the rest,

The roses first came red.

\section{LA PERSONIFICACIÓN DEL INSTRUMENTO DEL CRIMEN Y EL MAR- TIRIO RELIGIOSO}

El motivo de los objetos como culpables involuntarios del crimen, que hemos visto a propósito de la metamorfosis de la rosa, es característico del epigrama religioso en la poesía neolatina del siglo XVII, como puede atestiguar el siguiente poema de J. Bidermann (1633, p.18, Flagellum Christi sanguine purpuratum):

Iratus domini cum terga secare satelles

Nodoso inciperet terque quaterque flagro:

Noluit imperio refugum parere flagellum,

Mitius immiti dum cupit esse manu.

Sed parere manus cum porro saeua iuberet,

Iussa flagrum fecit. Fecit, et erubuit ${ }^{13}$.

\footnotetext{
12 Una traducción latina del poema de Herrick puede verse en Latin and Greek Verse Translations (Maclean 1880, p.21): Iampridem niueas est fama fuisse, deinde / quae prius alberent erubuisse rosas. / Est etenim lis orta ingens sua pectora uisu, / anne forent Sapphus candidiore meae. / Quum tamen haud dubio cedunt certamine uictae / continuo iratis occupat ora rubor. / Inde ferunt uates, facto uos credite amici, / quae prius albuerant erubuere rosae.

13 Ésta es la versión del texto que figura en algunas ediciones tardías (cf., por ejemplo, 1633, p.18 y 1732 , p.19). Otra versión puede leerse en otras ediciones (1620, p.4, 1621, p.12): Iratus Domini postquam nudata satelles / intento cupiit terga secare flagro; / saeuitiem uoluit refugum damnare flagellum, / immitemque inter mitius esse manum. / Sed parere manus cum cogeret impia, flagrum / in Domini tergo protinus erubuit. Similar transformación ha sufrido otro epigrama del autor que variaba el mismo motivo (In Sacrilegam manum, quae Christum cecidit, 1620, pp.10-11). En la versión original el texto concluye del siguiente modo: Scilicet erubuit Deus inter uerbera, quando / militis in dextra debuit esse rubor (vv.7-8) [«enrojeció Dios al ser azotado, aunque el rubor debió teñir más apropiadamente la diestra del soldado»]. En las otras ediciones, en cambio, el texto ha adquirido mayor extensión, con lo que llega a abarcar 10 versos, el orden de los dísticos ha sido alterado y el motivo del enrojecimiento ya no ocupa la posición final, sino que cierra la primera parte del texto: Erupit per aperta Dei rubor ora: sed illa / rectius in palma debuit esse rubor (vv.5-6: 1633, p. 20, 1732, pp.19-29).
} 
«Como el airado esbirro comenzara a flagelar con el nudoso látigo la espada del Señor tres y cuatro veces, rehusó el azote obedecer el mandato, deseando ser más clemente que la inclemente mano. Pero, como la cruel mano le mandara obedecer, tuvo que acatar sus órdenes. Lo hizo y se sonrojó.»

La conclusión fecit et erubuit cierra con su ambigüedad el texto; culmina, en efecto, la personificación del instrumento que se inicia ya en el segundo dístico, lo que permite entender la conclusión como una metáfora del látigo cubierto de sangre, o como un milagro.

Este motivo de un cambio natural explicado como fruto de la simpatía de los objetos es frecuente en la literatura y suele ir unido, como en este caso, al de los instrumentos como cómplices involuntarios del mal.

El motivo de los instrumentos inocentes del mal (variación del más general de la simpatía de los objetos) está muy extendido en la poesía occidental. En unos casos la fabricación de un objeto se nos presenta como la profanación de la inocencia original de la materia; en otros el instrumento creado para el mal demuestra más clemencia que la persona que lo utiliza. El árbol se quejará de ser utilizado para construir la horca, el hierro de servir como instrumento de tortura o para forjar la estatua del tirano y no para forjar arados. El tema va unido con frecuencia al motivo de la metamorfosis: el instrumento de tortura, calentado al fuego, 'enrojecerá' de vergüenza al tener que dañar a un inocente, o bien se aterrorizará tanto ante la magnitud de su crimen, que quedará rígido y se convertirá en estatua. La rosa, blanca antes de herir el pie de Venus, se ruboriza de vergüenza y se vuelve roja, etc ${ }^{14}$.

En los epigramas religiosos sobre los mártires el motivo del instrumento criminal da lugar a la comparación entre el instrumento del crimen y el personaje que se encarga de la tortura, como hemos visto en el poema de Bidermann. De este modo, en una rebuscada antítesis, las cualidades propias del objeto son atribuidas al ser humano, simbolizando su crueldad, mientras que al objeto inanimado se atribuyen cualidades humanas, mediante el recurso a la metáfora. Así, la sangre que cubre el instrumento de tortura se convertirá en el rubor del objeto al actuar como cómplice inocente de la crueldad humana.

Motivo paralelo al del enrojecimiento es el del endurecimiento o el ablandamiento de los materiales, como puede verse en el siguiente epigrama de J. Bidermann (1633, p.127, Christus, claua militis percussus) ${ }^{15}$ :

\footnotetext{
${ }^{14}$ Este tipo de motivos no es menos frecuente fuera de la literatura neolatina. Baste citar como ejemplo el acto cuarto de La vida y la muerte del rey Juan de Shakespeare, en que desarrolla extensamente las posibilidades del motivo.

${ }^{15}$ El desarrollo es casi idéntico al del poema anteriormente citado Iratus domini cum terga secare satelles. También en este caso hay una comparación entre la dureza del hierro y la del ejecutor. Como en el caso anterior el primer dístico presenta la situación. El adjetivo ferrea, que encabeza aquí el hexámetro, insiste en la dureza y crueldad del instrumento y el uso metonímico de claua como sujeto anticipa la personificación. El segundo dístico indica también en este caso el rechazo del instrumento de tortura a cumplir su función. Los verbos (horruit - cupiit) corresponden a los dos del epigrama anterior (noluit - cupit) y lo mismo ocurre con el comparativo (mitius en un texto y mollior en el otro). Finalmente, el último dístico desarrolla la comparación entre el instrumento y el esbirro y en ambos casos el uso de la metonimia manus, sirve para despersonalizar al personaje y equilibrar la comparación.
} 
Ferrea cum uinctum pulsaret claua Tonantem,

Barbaraque immeritum tunderet ira caput:

Horruit agnatum ferri natura rigorem,

Et cupiit pluma mollior esse chalybs.

Certe autem pluma cum mollior esse nequiret,

Militis incepit mollior esse manu.

«Al golpear la férrea maza a Nuestro Señor, mientras éste estaba atado, y al machacar la bárbara ira su inocente cabeza, se horrorizó la naturaleza del hierro de su innata dureza y el acero deseó ser más blando que la pluma. En verdad, no pudiendo ser más blando que la pluma, lo fue más que la mano del soldado.» ${ }^{16}$

El motivo del instrumento como cómplice involuntario puede variarse hasta la saciedad, adaptándolo a las circunstancias. Así podemos verlo en el siguiente epigrama del jesuita Vincenzo Guinigi (1588-1653), De S. Basilio ${ }^{17}$ :

Iam calamum cepit manus imperiosa tyranni

Unde tibi, o Basili, cederet exilium.

Ille auersatus mala munera, substitit insons,

Et nullam impressit exhibuitue notam.

Perfide, cui semper leuitas in pectore uixit;

A penna exemplum nunc grauitatis habes.

Illa sapit: siquidem huic pudet atramenta referre,

Cuius ab ingenii candida lacte fuit.

«Ya la imperiosa mano tomó la pluma para enviarte, Basilio, al destierro. Pero ella rechazando realizar un oficio malvado, se resistió para mantenerse inocente y no trazó ni ofreció a la vista señal alguna. ¡Pérfido! ¡Tú, cuyo pecho nunca albergó otra cosa que inconstancia! Puedes tomar ejemplo de gravedad de esta pluma, pues da muestras de sabiduría, ya que se avergüenza de manchar con su tinta el nombre de aquel cuyo ingenio fue cándido como la leche».

\footnotetext{
${ }^{16}$ Un concepto emparentado podemos verlo en otro epigrama del mismo autor que se basa en la identificación entre la situación representada y la obra de arte (De flagello depicto, et in Christi tergum intento, 1633, op. cit., pp.125-126). La inmovilidad de la representación artística se justifica como un milagro. El golpe del látigo (flagra) no acaba de ser descargado por haber quedado éste rígido a causa del miedo por el crimen que está a punto de cometerse: Criminis ipsa sui diriguere metu (v. 4). Un desarrollo similar se encuentra, por ejemplo, en un epigrama de E. Tesauro (Reuerendi patris Emanuelis Thesauri S.I. Caesares, et eiusdem uaria carmina. Quibus accesserunt Nobilissimorum Orientis et Occidentis Pontificum elogia, et uaria opera poetica, Oxonii, 1637, p.51, y 1652, p.52) sobre una estatua de Santa Úrsula (In S. Ursulae statuam cum lictoribus). El hacha esgrimida por el líctor, inmovilizada para siempre en la representación escultórica, no acaba de caer. El poeta concluye (vv.5-6): Haec reor est Pallas Virgo, nam pectoris albam / aegida cum peteret duruit illa manus («Ésta es -creo- la virgen Palas, pues la mano, al querer golpear el blanco escudo de su pecho, quedó convertida en piedra»). En estos textos el motivo va unido a la característica hipérbole condicional de los epigramas sobre obras de arte. Las figuras representadas se moverían de no ser por la influencia del santo; la estatua no habla porque la regla propugnada por el filósofo o el santo lo prohíbe, o, si se trata de una imagen de la Virgen María, porque no quiere despertar al Niño Jesús, etc.

${ }^{17}$ Éste es el texto del poema tal y como aparece en la edición de 1637 (p.236). En el resto de las ediciones el texto es algo diferente: en lugar del v. 2 puede leerse Qui graue Basilio scriberet exilium y el dístico final dice así: Et sapit haec: siquidem nigro inficienda colore / Candida Basilii nomina non fuerant (Romae, 1627, p.194; Antuerpiae, 1633, p.159; Parisiis, 1639, p.184).
} 
La referencia metonímica a la mano, la resistencia del objeto al que se dota de voluntad propia, la comparación entre la persona y el instrumento y el simbolismo que se confiere finalmente al color negro de la tinta evidencian la relación entre este texto y los epigramas de Bidermann antes $\operatorname{citados}^{18}$.

\section{AMBIVALENCIAS SIMBÓLICAS}

En una serie de epigramas neolatinos basados en la ambigüedad simbólica del color rojo, encontramos un desarrollo similar al de los poemas anteriormente citados. Un ejemplo es otro de los epigramas sacros de Bidermann (1732, p.35, S. Cyrilla, Virgo Martyr, Decii Tyranni filia, Decii Caesaris soror):

Si neque Phocaicae fratri sua purpura lanae

Profuit; Ausonium nec diadema patri,

Nil mihi uobiscum est: diadema facesse; ualete

Omnia Cadmeo uellera missa Tyro.

Nobiliore tuli bis tinctas murice uestes,

Sanguine dum didici Virgo rubere meo.

«Si ni la púrpura de la lana focea valió a mi hermano, ni la corona de Italia a mi padre, nada tengo que ver con vosotros. ¡lejos de mí, corona, adiós toda la púrpura enviada por la fenicia Tiro! Porté una ropa teñida doblemente con una púrpura más noble, al aprender siendo doncella a sonrojarme con mi sangre».

Aquí la sangre es una vez más una forma de rubor. El juego simbólico se desenvuelve a partir de la oposición entre la púrpura (emblema de realeza y, por tanto, de poder y de gloria) y la humildad propia del cristiano, por una parte, y, por otra, entre la violencia y la sangre que el tirano derrama y la sangre vertida y ofrecida en sacrificio por los mártires. El rubor de la joven puede entenderse como alusión a la sangre del martirio o como referente al pudor de la doncella, martirizada por no querer abandonar su condición virginal, ni casarse, al estar ya desposada con Cristo.

Similar contraste se encuentra en este epigrama del jesuita Badouin Cabilliau (15681652), Maximianus (1614, p.121, 1634, p.120) ${ }^{19}$ :

\footnotetext{
${ }^{18}$ El también jesuita P. Alois aplicó el motivo a la circuncisión de Jesucristo (1635, p.75, 1646, p.230). La sangre corre roja de la herida, pero antes -afirma el poeta- era blanca. Y concluye que ha enrojecido por no poder fluir más abundantemente (v. 6. quod fluat in guttas parcior, erubuit). El tema de la circuncisión de Cristo era habitual en el epigrama sacro de la época y el contraste entre sangre y leche era común en las leyendas referentes al martirio de distintos santos, especialmente S. Pablo.

${ }^{19}$ La asociación entre púrpura y sangre vertida para conseguir el poder, que hemos visto en el epigrama de Bidermann, es frecuente en los epigramas de Cabilliau, en varios de los cuales se repite además el tema del sacrificio de los hijos inocentes a causa del poder paterno. Así, por ejemplo, en el epigrama sobre Maximino el Tracio, el deseo del padre de que el hijo sea su heredero causa la muerte de muchos senadores y a la postre la suya propia y la de su propio hijo (1614, p.118): Ut trabeam puero tingas, cruor incoquit ostro / patricio, hostili purpura caede rubet. / Ah nimium hoc pretium! Poteras tinxisse minoris, / ipse tuo intinges sanguine; carus emes. En otro texto (1614, p.139) el autor glosa la caída en desgracia de Estilicón y su muerte, junto a la de su hijo, en los siguientes términos: Trama trahit tramam, densatur uellere uellus, / de filo in filum tela perennat opus. / Purpura sola deest. Trabeam uis tingier ostro? / Qui tingat gemina de nece sanguis erit.
} 
Infelix in probra decus, tibi purpura, tingi Quo non debuerat sanguine, tincta rubet. Non tam, crede mihi, Tyrio rubet ebria succo, Quam domini obscenum dedecus erubuit.

«Infeliz honor que te condujo a la infamia, la púrpura enrojece para ti teñida con sangre indebida. No enrojeció tanto ebria por el jugo de Tiro, créeme, como por el obsceno deshonor de su dueño».

En estos epigramas el texto se basa en una forma de antítesis metafórica. En el epigrama de Bidermann la púrpura del poder se contrapone a la auténtica púrpura, la del martirio. Se trata de una forma de antítesis característica de los epigramas fúnebres en general y en especial de los epigramas sobre los mártires. El comparativo nobiliore en este tipo de desarrollo constituye un cliché, muy frecuente en la poesía neolatina, especialmente en los epigramas fúnebres y cuyo origen se encuentra en Marcial (11.69.12: non potui fato nobiliore mori).

En el epigrama de Cabilliau sobre Maximiano la antítesis opone dos metáforas, explotando siempre la ambivalencia del color rojo, en una doble antítesis; de ahí las repeticiones que enlazan los versos de ambos dísticos: tingi - tincta / rubet - erubuit. En el primer dístico se contraponen una vez más las dos facetas simbólicas del rojo, que evoca a la vez el poder y la crueldad de la sangre de los otros derramada o de la propia, porque el destino del tirano es morir violentamente. En el segundo se repite la misma oposición, pero frente a la objetividad del primer dístico, en este caso la antítesis se tiñe con los matices del sentimiento: el rojo simboliza ahora, por un lado, la ebriedad del poder (el aspecto negativo del poder y la gloria representado por la tez roja producto de la ebriedad) y, por otro, la sangre se convierte en el último dístico en el rubor que aflora a causa de la vergüenza. Paralelamente el decus del primer verso se convierte en el dedecus del último. Como en los epigramas referentes a los instrumentos inocentes del crimen, el objeto enrojece de vergüenza ante la conducta de su portador.

No menos sofisticado es el siguiente poema del jesuita napolitano Pietro Alois (15851667), In Roberti Bellarmini Cardinalis e S.I. effigiem (1646, p.29):

O quicumque inhias Romano feruidus ostro,

Hanc cupida effigiem mente reconde memor.

Aspice purpureus pendet post terga galerus,

Ne sua luminibus retia tendat Honor:

Diua Deum complexa oculis datur obuia Virgo,

Ut sua luminibus retia tendat Amor.

Diua, tuis, natique impar fulgoribus ostrum

Post tergum latitans erubuisse reor.

«Tú, quienquiera que ansías poseer la púrpura de Roma, mantén viva en tu ávida mente esta imagen. Contempla cómo el capelo purpúreo cuelga a la espalda, para que Honor no tienda sus redes para atrapar los ojos del cardenal. La Santa Virgen abrazando al niño Dios se le presenta de frente, para que Amor tienda sus redes para atrapar sus ojos. ¡Virgen santa! La púrpura, incapaz de igualar tu brillo y el de tu hijo, escondiéndose tras la espalda, enrojeció de vergüenza». 
La disposición de la imagen representada permite al poeta glosar el contraste entre la ambición por el poder asociada con la púrpura cardenalicia y la devoción que debe guiar al cristiano. La contraposición entre ambición y modestia da lugar al contraste alegórico entre Honor y Amor personificados y entre el brillo que emana de la Virgen con el Niño y el rojo del capelo cardenalicio ${ }^{20}$.

Resulta significativo que el poema de Alois se refiera a un cuadro y no al personaje real. La forma en que el autor interpreta el esquema formal de las figuras del cuadro y la familiaridad con los aspectos simbólicos de la imagen traiciona la mente entrenada en las sutilezas del arte emblemático propio de la época. También los epigramas anteriormente citados sobre la ambigüedad simbólica de la púrpura imperial evidencian el mismo tipo de orientación artística y dan muestra de un esquema simbólico idéntico ${ }^{21}$.

En los epigramas citados el ropaje tiene el carácter de un signo convencional: el color rojo indica convencionalmente en tal contexto que se trata del emperador o un cardenal. Tales signos, al igual que ocurre en general con las enseñas como la cruz, la media luna etc., mantienen, por otra parte, una relación indicial, de coexistencia, con el objeto o la persona a la que acompañan: la cruz indica que un ámbito o una persona son cristianos, la ropa de un color determinado, que la persona en cuestión tiene tal condición social, etc. Pero dichos signos tienen además carácter simbólico, definiendo en cierto modo a la persona o al objeto al que acompañan o el cargo que representan. De esta manera el negro, por ejemplo, indicará, como signo convencional, que la persona está de luto, pero además el color negro representa simbólicamente la naturaleza de la muerte o del dolor de las personas allegadas ${ }^{22}$.

Resulta interesante que las implicaciones simbólicas a las que hemos hecho referencia a propósito del atuendo cardenalicio e imperial estén también conectadas con el simbolismo de la rosa, como podemos ver en los tratados sobre emblemas y empresas de la época. En el Mondo simbolico ampliato de Picinelli se habla, por ejem-

\footnotetext{
${ }^{20}$ El poema adopta una disposición anular con la clara oposición de Honor y Amor en los dísticos centrales y el contraste paralelo entre el primer dístico y el último, marcado por la repetición de ostrum como última palabra del hexámetro en ambos casos.

${ }^{21}$ El propio P. Alois (1646, pp.25-26) utilizó la ambigüedad simbólica del rojo y de la púrpura, que en los dos textos anteriores da lugar a una antítesis dentro del mismo texto, en una pareja de poemas especulares, que se contraponen también antitéticamente. En el primero (Ad Franciscum Cardinalem Barberinum Sidonia Doris) la ninfa del mar fenicio envía al cardenal la púrpura y, a cambio, le pide una sola cosa: Augusta ut Tyrio tibi uellera tinximus ostro, / Treïcio fluctus sanguine tinge meos («Del mismo modo que hemos teñido tu augusto atuendo con la púrpura de Tiro, tiñe tú mis olas con la sangre turca»); en el segundo texto (Ad Antonium Cardinalem Barberinum Tyrrheni maris Syren), la ninfa del mar occidental lamenta no disponer de los mismos recursos que su equivalente oriental para enviar su ofrenda y el poema concluye (vv.5-8): Tyrrhenus Tyrio careat quod Nereus ostro, / inficior tristes ore rubente genas: / Iam rea sum uoti; nostro rubor ingruit ore; / hic pro Sidonio murice munus eat («Porque el mar Tirreno carece de la púrpura de Tiro, mis mejillas se tiñen tristes de rubor. Ya soy culpable por mi deseo: el rubor se ha adueñado de mi rostro. Valga él mismo como regalo»).

${ }^{22}$ En un epigrama de Bidermann (In funere Philippi Cardinalis, 1621, p.192, 1633, p.269, 1732, p.192) se afirma que las ropas del personaje "enrojecieron" con su dueño al obtener éste la dignidad cardenalicia: Ausonii caperes cum iura, Philippe, senatus, / in domino uestes erubuere suo (vv.1-2); a su muerte se cambian en negro: Et simul in tristem uestes abiere nigrorem; / purpureusque togae coepit abesse rubor. / Hinc suus ergo color iam desiit esse Galero; / quando suus domino desiit esse color (vv.5-8).
} 
plo, a propósito del simbolismo de la rosa de un arzobispo del que se esperaba que llegara pronto a la dignidad de cardenal, que adoptó como empresa un botón de rosa, aún no abierta, con el lema mox erubescit, aludiendo a su futura promoción eclesiástica; el autor justifica la ambición del prelado por la premonición del martirio, y concluye que es legítimo desear las dignidades eclesiásticas en aquellas circunstancias en que éstas garantizan el martirio (1669, p.528, 1681, p.672). La rosa como símbolo de humildad se encuentra en el Apelles Symbolicus (Von Der Ketten 1699, II, p.57) con el lema Victa pudore rubet («vencida, de la vergüenza enrojece»). La conexión simbólica con la dignidad cardenalicia y con el martirio puede verse en la imagen de varias rosas naciendo de un mismo tronco con el lema Tot in uno stipite rubent («Tantas enrojecen en un mismo tronco») $)^{23}$. La ambigüedad simbólica y la conexión de la rosa con el rubor y la vergüenza ante los actos de otros se puede observar en la empresa de San Bernardo avergonzado ante la obscenidad de sus interlocutores representado por una rosa (Von Der Ketten 1699, II, pp.55-56), con el lema Sine crimine rubet («Sin culpa enrojece») $)^{24}$.

Picinelli muestra también la ambigüedad simbólica de la rosa como símbolo a la vez de la pasión y de la vergüenza, así como su conexión con el cliché que nos ocupa, citando a propósito de la rosa como emblema del placer en cuanto efímera recompensa de la pasión amorosa unos versos de la Mythologia de Natale Conti (1568, p.123): Nihil est amor Veneris, quam parua uoluptas, / quae simul expleta est, inficit ora rubor («El amor no es otra cosa que la pequeña recompensa de placer que ofrece Venus. Tan pronto como se ha saciado, el rubor tiñe tu rostro») ${ }^{25}$.

\section{LA ROSA Y EL CORAL}

Con la constelación simbólica y temática de los poemas anteriormente citados podemos comparar el siguiente texto de Giuseppe Silos sobre una imagen de S. Francisco hecha de coral (Diui Francisci effigies Coralina) ${ }^{26}$ :

${ }^{23}$ Ibidem, II, p.58. En el Mondo simbolico ampliato (Picinelli 1669, p.454) puede verse también el uso del símbolo de la vid a propósito de la promoción de otro religioso al cardenalato con el lema: Matura rubuit («Al madurar, enrojeció»), lema que también podría aplicarse - nos dice el autor- al martirio de Cristo.

${ }^{24}$ Significativamente, el mismo lema es utilizado con el símbolo de la espada (1699, II, p.398) acompañado del siguiente epigrama (Augusto II. iusta et sacra bella gerenti): Saepe rubent gladii, sed non sine crimine semper. / Saepius innocuo sanguine, nempe rubent. / Regius ERUBUIT semper SINE CRIMINE mucro, / hostili rutilat sanguine, quando rubet.

${ }^{25}$ La expresión uidit et erubuit es utilizada en el primer dístico de un poema de la Magdalena de Cabilliau titulado Magdalena monstrum mutatur in Diuam pulcherrimam (1625, p.199): Ut septena nocens Lernaei cornua monstri / monstrifero speculo uidit, et erubuit Magdalis. En este contexto la frase sirve tan sólo para indicar la vergüenza. La protagonista se ve a sí misma como un monstruo. La expresión hay que entenderla, sin embargo, en el complejo juego simbólico del texto, donde el autor explota también la dualidad de Medusa (monstruo / mujer hermosa), el contraste entre la cabeza serpentina de Medusa y la corona de espinas de Cristo, etc. Al final del texto Magdalena aparece transfigurada y el enrojecimiento de la vergüenza se transforma en el rubor del pudor: Frons modo silua feris, iam rosa uiua rubet (v. 20).

${ }^{26}$ Epigrama 3.9 (1650, p.283; 1652, 1655 y 1658, p.307). 
Cui toga pauperior, cinerique simillima; puram

Cui liquidus frontem pinxit, et ora cinis,

Coralio spirat uiuo: en qua diuite gemma

Effinxit uultus ingeniosa manus.

Pallida non olli facies; iam purpurat omnis,

Ora rubent, ardet purpura uiua genis.

An cruor it uultu, roseoque ebullit in ore,

Plurima dum niueo in pectore flamma calet?

Fallor: pauperies semper cui gratior una,

Se gemma insculptum uidit, et erubuit.

«Aquel que poseyó en vida un pobre ropaje, semejante a la ceniza, y cuya frente y rostro tiñó una transparente ceniza, respira ahora en el coral vivo. ¡Con qué rica gema representó su cara la ingeniosa mano! Su faz no es ya pálida, ya se llena todo él de púrpura! Su rostro se ruboriza; arde en sus mejillas al rojo vivo la púrpura. ¿Se ha llenado acaso de sangre su rostro? ¿brota hirviente la llama, que arde excesiva en su blanco pecho? Me equivoco. Aquel a quien fue sólo grata la pobreza se ha visto esculpido en la gema y ha enrojecido de vergüenza».

La metamorfosis por modestia ante el honor recibido involuntariamente es un motivo opuesto al del instrumento culpable contra su voluntad. Común a ambos es el simbolismo de la materia, que puede adoptar dos vertientes diferentes, según la materia corresponda o no al objeto o a la función de éste. En los poemas sobre las implicaciones simbólicas del atuendo del poder, la púrpura imperial o cardenalicia, el texto explotaba la ambigüedad simbólica del color, que puede evocar, por una parte, el poder y la soberbia a él unida, así como la sangre de los otros, vertida a cambio de conseguir la gloria, o derramada por el propio sujeto, como destino final que aguarda al tirano, y, por otra, inversamente, la humildad con que debe accederse al ejercicio del poder, propia de aquel a quien se concede un honor que lo coloca por encima de los demás, y la vergüenza ante la crueldad de los otros. De esta forma, en estos textos, todo ocurre como si se juntaran a través de la antítesis los dos temas opuestos de la culpabilidad involuntaria y la modestia por el honor inmerecido.

En el poema de G. Silos sobre S. Francisco se parte del contraste entre la materia de que está hecha la imagen y el carácter del personaje. Es una variación de un tema común en los epigramas sobre obras de arte ${ }^{27}$. Al igual que ocurre a veces con la púrpura, que, como símbolo del poder, contrasta con la persona humilde, en este caso la materia de la joya contrasta con el personaje representado, que encarna la pobreza

\footnotetext{
${ }^{27}$ El epigrama de G. Silos forma un díptico con el epigrama anterior (3.8, In ceream D. Magdalenae effigiem), que explota el simbolismo de la materia de la obra de arte (1650, pp.282-283; 1658, p.307), a través de un motivo tradicional desde el epigrama griego, el de la estatua de cera del enamorado o de Cupido. La cera es materia inadecuada para un dios que no es otra cosa que fuego, mientras que, por el contrario, resulta material apropiado para representar al enamorado, pálido por el sufrimiento y que se consume como una vela. En el caso de Magdalena, su figura encarna tanto la pasión amorosa como el arrepentimiento y el derramamiento de lágrimas, ideas que se funden poéticamente en la imagen de la cera que se consume. La conexión con el epigrama anterior refuerza, por otra parte, en el caso del poema sobre S. Francisco, el tema del amor que sirve de fondo al texto.
} 
como elección vital. La metamorfosis recuerda la de los instrumentos del martirio, pero en este caso se debe a la modestia.

Junto a este desarrollo hay otro meramente sugerido, rechazado en el plano literal, pero que desde el punto de vista literario introduce otro plano de significación en el texto: el del contraste entre la palidez propia del enamorado y el fuego de su pasión, que se expresaría en la sangre acumulada en sus mejillas, como indicio de vergüenza. De este modo, también en este caso, aunque el contraste no se expresa mediante antítesis, estamos una vez más ante una ambivalencia simbólica, al asociarse el color rojo del coral con el rubor de la modestia y de la vergüenza, o con la sangre y el sentimiento del amor. Naturalmente a nivel poético ambos planos de significado están relacionados, pues el amor por Cristo explica la adopción de la pobreza como elección vital.

Es casi innecesario hacer notar la similitud existente en la literatura emblemática entre el simbolismo del coral y el de la rosa y de la púrpura. Dicha semejanza puede advertirse en el uso del coral como símbolo de la elevación a la dignidad cardenalicia y también, como en el caso de la rosa y de la púrpura, se asocia al pudor de la modestia y a la sangre del martirio. En el Apelles symbolicus podemos encontrar varios ejemplos de este uso del coral (Von Der Ketten, 1699, II, pp.72-74). Así, el lema Aliquando rubebo, referido al coral antes de su transformación, puede ser empresa de un hombre que ansía ardientemente el martirio o que aspira a la púrpura del poder. Rubet in alto puede aplicarse a un hombre que se muestra modesto al recibir honores. Sponte rubebunt se aplica fácilmente a las personas modestas por naturaleza, mientras que Morte rubebunt es lema apropiado para los mártires.

La asociación simbólica de la rosa y el coral puede verse en el siguiente poema de B. Cabilliau, Coralium cum rosa collatum (1614, p.277):

\section{Germen aquae ut purum uidere roseta corallum, \\ Victa uerecundis erubuere genis. \\ Alma suo Natura rosas ante induit ostro, \\ Nunc ueniet uictis altera causa pudor.}

«Al ver los rosales al coral, brote puro del agua, el rubor se apoderó de sus mejillas llenas de pudor. La madre Naturaleza revistió antes las rosas con su púrpura. Ahora, vencidas, el pudor tendrá sobre ellas el mismo efecto».

Una vez más se evoca la metamorfosis de la rosa. Pero el coral se presenta aquí como símbolo superior al de la rosa y la ficción sirve de vehículo a una comparación. Las rosas se confiesan vencidas por el coral. La naturaleza cede ante el espíritu. Al simbolismo de la rosa se contrapone en este caso la pureza del coral, que al tiempo que hereda la valencia simbólica de la flor le añade su carácter más evidente de símbolo espiritual. El coral representa, por así decirlo, la sublimación de la rosa.

También en el caso del coral su simbolismo es ambiguo. Al simbolismo del color el coral añade el motivo paralelo del endurecimiento como consecuencia de la transformación, de forma que en la imaginación poética el coral supone el paso de la inmersión en el agua al universo celeste y abierto, y aúna al tiempo los reinos vegetal y mineral, motivo este que está además asociado poéticamente con el tema de la vi- 
sión, pues, según el mito, el coral nace de las gotas de sangre vertidas del cuello de la decapitada Medusa, monstruo mitológico que tenía precisamente la propiedad de petrificar con la mirada. Al igual que la rosa, está, pues, relacionado con la mitología de nacimientos prodigiosos originados por la sangre de los héroes.

La metamorfosis del coral puede ser interpretada poéticamente como algo positivo o negativo. En sentido positivo la transformación del coral podrá representar la exaltación al poder cardenalicio o la adquisición de la belleza tras la conversión espiritual, el mayor valor de la espiritualidad, la firmeza y solidez del cristiano en los asuntos espirituales, frente a su debilidad en cuestiones terrenales, el abandono de la sordidez del pecado, etc. Todo ello podrá expresarse mediante lemas como Aethere durescit, o bien Indurabitur o Auulsum pretiosius. Praecidimur sed gemmascimus, es, una vez más, emblema del mártir decapitado (Picinelli 1681, p.688) ${ }^{28}$. Inversamente, podrá representar también el endurecimiento espiritual de quien reniega de lo espiritual o se entrega a la fascinación por el pecado, al apóstata, etc. El coral acompañado del lema In lachrymis tantum uiuo, es emblema de Magdalena o de cualquier alma arrepentida. Con el lema Rubor de matre relicta representa al apóstata y Cum matre uirebam a la doncella que se ha dejado corromper ${ }^{29}$.

\footnotetext{
${ }^{28}$ Este valor simbólico del coral puede verse en un epigrama de Étienne Forcadel, De Corallio et mente humana (1554, p.108), que podría servir perfectamente para ilustrar las palabras de Picinelli. Las profundidades del mar de las que emerge el coral representan en el poema de Forcadel la ofuscación de lo mundano frente a la luz celeste. El coral, debido a su conexión con los distintos reinos de la naturaleza y a su relación con las profundidades, puede representar así la creación y la purificación de lo material en espiritual:
}

In Siculo ramosa leges Corallia ponto, Vilia sunt in aquis, sed pretiosa foris.

Nanque frutex sensim lapidescit in aëra surgens, Et rubra pro tenui germine gemma nitet.

Sic hominum sordet fluctu mens obruta mundi, Libera quae scandens aethera, lumen habet.

«En el mar siciliano recogerás los corales, que semejan ramas. En las aguas son poco valiosos, pero fuera se convierten en preciosas joyas. Pues el vegetal ramaje, al alcanzar cielo abierto, se convierte poco a poco en piedra y la gema rioja brilla en lugar de los débiles brotes. Así, la mente de los hombres, mientras se mantiene sumergida en el oleaje del mundo, es impura, y al ascender al aire libre adquiere luz».

${ }^{29}$ El simbolismo negativo del coral puede verse, por ejemplo, en el siguiente poema de G. Herbert (1892, p.357, Lucus, 1, Homo, statua):

Sum, quis nescit, Imago Dei, sed saxea certe: Hanc mihi duritiem contulit improbitas.

Durescunt propriis euulsa coralia fundis:

Haud secus ingenitis dotibus orbus Adam.

Tu, qui cuncta creans, docuisti marmora flere,

Haud mihi cor saxo durius esse sinas.

«Soy - ¿quién lo ignora? - imagen de Dios, pero de piedra ciertamente. El pecado es la causa de esta dureza mía. El coral, al ser arrancado de sus fondos, se endurece. Del mismo modo, Adán se ha visto privado de sus cualidades primigenias. Tú, que al crear el mundo enseñaste al mármol a llorar, no dejes que mi corazón sea más duro que una roca.» 


\subsection{LA TRANSUBSTANCIACIÓN DEL AGUA EN VINO}

Sin duda, el ejemplo más famoso de este tipo de conclusión es el poema de Crashaw sobre las bodas de Caná (Joann. 2, Aquae in uinum uersae), con el que hemos iniciado nuestra exposición $\left(1634\right.$, p.37) ${ }^{30}$ :

\section{Unde rubor uestris et non sua purpura lymphis? Quae rosa mirantes tam noua mutat aquas? Numen (conuiuae) praesens agnoscite Numen: Nympha pudica Deum uidit, et erubuit.}

«¿De dónde le viene el rubor a vuestras aguas y esa púrpura que no les es propia? ¿Qué rosa tan nueva transmuta las sorprendidas aguas? Un dios está aquí; reconoced, comensales, su presencia. La ninfa ha visto a Dios y, llena de pudor, ha enrojecido».

Sorprende la gran divergencia de las diferentes traducciones, adaptaciones e interpretaciones que se han dado de este poema. El proceso de independización del verso final debió empezar pronto ${ }^{31}$. Una vez convertido en frase proverbial, de autoría ignorada o discutida, el verso fue citado de muy distintas formas. El término nympha fue reemplazado con frecuencia por lympha (que aparecía de hecho en el primer verso del epigrama original), dentro de una lectura puritana, renuente a la alusión mitológica -como incompatible con la dignidad religiosa del tema- $\mathrm{y}$ a las resonancias sensuales del vocablo ${ }^{32}$. Quizá por razones similares, el adjetivo pudica es substituido a veces en las citas por conscia, lo que elimina en parte la implicación con respecto al contexto nupcial y el paralelismo entre los protagonistas del milagro, el agua y Cristo, y la pareja marido - mujer. Se resalta, en cambio, la condición milagrosa del acontecimiento, como testimonio del poder divino, lo que en el texto original estaba acentuado por el agnoscite, que enlazaba en este sentido con el uidit. Finalmente, la cláusula final, uidit et erubuit, se invierte en ocasiones con lo que el verso es citado así: Vidit et erubuit lympha pudica Deum.

En este caso es la separación de la divinidad la que origina la transformación. La comparación del hombre arrojado del paraíso con el coral es, por otra parte, un tema inverso al de la simpatía de los elementos. Si el contacto o la presencia de la divinidad o del santo provocan en aquellos la transformación, la separación de la divinidad tiene el mismo efecto y la oposición entre blandura / dureza de los materiales como símbolo de inocencia / culpabilidad corresponde a este tipo de motivos.

${ }^{30}$ Cf. 1670 y 1674, pp.29-30, 1858, p.299, Williams 1972, p.305, y Laurens 1975, p.503.

${ }^{31}$ En la edición bilingüe de 1682 (p.7, epigr. 18) el poema aparece reducido ya al dístico final, que va acompañado de la siguiente versión en inglés: See, ô my Guests: A deity is here: / The Chast Nymph saw a God, and blusht for fear. La versión inglesa ofrece una razón, el temor reverencial, para el rubor que se apodera del agua, que carece de paralelo en el texto latino, aunque puede haber sido sugerida por el mirantes del desaparecido segundo verso del epigrama y, por lo demás, el pudica del verso latino se ha convertido en casta, lo que, unido al cambio citado, supone una orientación del texto en un sentido determinado.

${ }^{32}$ Lo contrario ocurre en la adaptación que Victor Hugo hizo de este verso: La Nymphe de ces eaux aperçut Jésus-Christ, / Et son pudique front de rougeur se couvrit (cf. Victor Hugo raconté par un témoin de sa vie, en Victor Hugo 1885, p.212). En esta adaptación se acentúa la personificación, pero el verso pierde gran parte de sus implicaciones, a pesar de la explicitación "ninfa de las aguas" y la referencia a Jesucristo, en lugar del genérico numen latino, cambios necesarios para dejar claro el contexto del que se habla. 
Como puede verse, en estas citas parciales el texto es interpretado en una dirección determinada y despojado de parte de sus implicaciones. Junto a las razones ideológicas y de contenido pueden también haber pesado en este proceso motivos puramente estéticos. Son muchos los lectores que parecen haber experimentado ante este poema un sentimiento de contradicción entre el carácter ingenioso del texto y la experiencia de lo sublime que conlleva. Si el ingenio bordea lo sublime, uno y otro acaban por quedar arruinados ${ }^{33}$. ¿Es la sorpresa propia de las agudezas epigramáticas -podrá plantearse en ese caso- un recurso poético legítimo?

Se trata del tipo de sentimientos que provocó el cambio de gusto que hizo que la literatura occidental dejara atrás la poesía demasiado artificiosa del barroco. La problemática latente era, por lo demás, antigua y tampoco habría de acabar aquí; era inherente a la poesía conceptista y habría de dar lugar a numerosas polémicas literarias antes y después de esta época. Para el moralista el artificio literario no quedará nunca justificado por sí mismo, sino sólo como modo de expresión de una verdad más profunda, que de otra forma sería inexpresable para el lenguaje humano.

No pocos lectores parecen haber preferido leer este verso como una intuición poética, fruto de un instante de iluminación, rehuyendo así la carga conceptual que el texto original conlleva. Lafcadio Hearn en su Kwaidan, recuerda el último verso de este poema, al hablar del haiku japonés, género oriental que compartiría con el texto que nos ocupa, según él, el gusto por los juegos de palabras y la simpatía por la naturaleza y lo pequeño $\left(1904\right.$, p.186) ${ }^{34}$.

Razones, pues, a la vez ideológicas y estéticas pueden explicar este progresivo adelgazamiento del poema y del verso, concebido como un momento de iluminación, una reacción ingenua e intuitiva ante el milagro.

\subsection{EL DESARROLLO DEL TEXTO}

En el cuidadoso engarce de unos términos con otros que Crashaw hace del vocabulario del poema, el autor utiliza tres términos relativos al color del vino: rubor, purpura y rosa. Los tres implican matices diferentes. Rubor enlaza con la personificación de erubuit; purpura insiste en la condición no natural (non sua) del color y contrasta con la humildad de la materia. En cuanto a rosa, aparece en relación con la idea de transubstanciación (mutat), lo que parece sugerir una metamorfosis a la manera ovidiana.

Los cuatro versos del texto latino presentan ese aspecto de cuidado artificio verbal y conceptual tan característico del epigrama de la época. El poema se ajusta, por

${ }^{33}$ Así S. Smith (1856, p.221) dice con respecto a este poema:

Now, in my mind, that sublimity which some persons discover in this passage is destroyed by its wit; it appears to me witty, and not sublime. I have no great feelings excited by it, and can perfectly well stop to consider the mere relation of ideas. I hope I need not add, that the line, if it produce the effect of a witty conceit, and not of a sublime image, is perfectly misplaced and irreverent: the intent, however, of the poet, was undoubtedly to be serious.

34 Traducción castellana $1962^{3}$, p. 113 . 
otra parte, a la bipartición epigramática, uno de los desarrollos más comunes del epigrama, hasta el punto de haber sido considerado por Lessing como el modelo esencial del género ${ }^{35}$. Dicho desarrollo fue teorizado ya por los tratadistas del XVII que se ocuparon de la teoría del género epigramático, y era considerado por ellos como característico del epigrama ingenioso a la manera de Marcial. Hay, pues, una clara diferencia entre los dos dísticos. La presentación de la circunstancia temática, en una primera sección narrativa o descriptiva, va seguida de la cláusula final, en la que el poeta nos ofrece su particular visión. De hecho, el texto adopta un desarrollo explicativo ( $a$ ratione reddita), característico de este tipo de composición. Así, los datos de la situación (conocidos, por otra parte, por el lector) se encuentran ya en el primer dístico. La conclusión del texto no aporta en realidad ninguna información nueva, sino una visión, una percepción distinta de la realidad. En este final del texto el lenguaje adopta, pues, una perspectiva onomasiológica, con lo que el componente ideativo y figurativo del lenguaje predomina sobre el referencial.

El salto en el uso del lenguaje entre ambas secciones del texto no supone, sin embargo, una auténtica separación entre una y otra. La situación, en efecto, se nos presenta como percibida a través de los ojos de un espectador y la conclusión es sólo la revelación final. El poema está, así, dramatizado, pues interpela en primer lugar a las propias aguas y después a los invitados del banquete, dando lugar a una significativa ambigüedad con respecto a la situación enunciativa ${ }^{36}$. El texto puede entenderse como enunciado por un asistente al banquete o por alguien que en la actualidad lo percibe como si estuviera sucediendo en el presente. Esta ambigüedad pragmática no sólo confiere vivacidad poética al poema, sino que presenta el milagro como algo continua y sacramentalmente renovado y cuya lección aún perdura.

Por otra parte, la conclusión está sutilmente preparada desde el primer verso por el uso del vocabulario. La agudeza no constituye en realidad la irrupción de una perspectiva nueva sobre los hechos, sino la revelación final de la perspectiva desde la que los acontecimientos se percibían desde un comienzo. Como ya hemos indicado, el final no aporta información nueva y el texto se presenta como una progresiva revelación. Este hecho está marcado por la correspondencia en quiasmo entre rubor y lymphis, situados en ambos extremos del hexámetro inicial y los términos nympha y erubuit en los dos extremos del pentámetro final. Los términos, emparentados etimológicamente, se suceden, pues, así: rubor (a) - lymphis (b) - nympha (b) - erubuit (a). La agudeza del pentámetro final cierra el texto. De este modo ambos versos vienen a decir prácticamente lo mismo, pero el verso final implica una percepción más rica de la realidad. Nympha pudica y erubuit combinan metáfora y ambigüedad. La frase puede entenderse como una simple metáfora del cambio de color de las aguas, pero también como una personificación mitológica en la que el agua reacciona ante la

${ }^{35}$ Cf. sobre el origen y desarrollo de la teoría de la bipartición del epigrama Ruiz Sánchez 2004-2005, pp. 163-210.

${ }^{36}$ Más convencional es, por ejemplo, la adaptación del poema, obra de A. Hill, en la que el primer dístico presenta los hechos, mientras la ficción enunciativa se reserva para el dístico final (1753, p.241): «When Christ, at Cana's feast, by power divine / Inspired cold water with the warmth of wine, / "See," cried they, while in reddening tide it gushed, / "The bashful stream has seen its lord and blushed!"». 
presencia del dios. La personificación está facilitada por la equivalencia fonética entre Lympha y Nympha. Como en la mitología tradicional las ninfas son encarnaciones de las aguas de fuentes y ríos, el término nympha es polisémico en el lenguaje poético, pues puede utilizarse metonímicamente para designar el agua (especialmente de una fuente).

El cultismo poético lymphis en el primer verso (frente al neutral aquas del segundo) anticipa el nympha del verso final. La derivación metonímica lympha $>$ Nympha nos sitúa dentro del universo mítico, facilitando así el sutil paso de la metáfora convencional rubor a la metáfora final erubuit, que implica una personificación. Varios aspectos del término lympha resultan interesantes en este contexto: lympha es, en primer lugar, un doblete lingüístico de nympha; la grafía refleja probablemente la helenización de lo que era un préstamo antiguo del griego, donde la disimilación explica la diferencia consonántica. Es, por otra parte, un término amado por los poetas, como sinónimo poético de aqua, a cuyo sentido básico el término añade un matiz de personificación y divinización; especialmente lo usan los poetas, sin duda por la conexión con nympha, para poner de relieve el rumor del agua; lymphae loquaces es el agua murmurante o bulliciosa, agua locuaz, alegre, femenina y voluble, encarnación de lo femenino; el vocablo servía también en poesía para resaltar la transparencia del agua; lymphae son las aguas cristalinas y limpias (no en vano lympha está muy próxima en la pronunciación de limpidus, y ambos términos quizá estén etimológicamente emparentados), lo que aumenta en el epigrama el contraste entre la materia, el agua, y el resultado de su metamorfosis. En el otro extremo de la equivalencia, nympha remite en latín y en griego, no sólo al universo mitológico, sino que puede significar también 'mujer núbil', 'doncella' y 'amante'. El rubor del texto podría corresponder así al de la doncella núbil ante su prometido, dentro del contexto nupcial del epigrama ${ }^{37}$.

El desarrollo explicativo establece una relación de signo / significado entre las dos partes del texto. El segundo dístico explica aparentemente el significado de la metamorfosis en el primero. Algo que está marcado por el agnoscite del verso 3. El milagro de la transformación se convierte así en un lenguaje de las cosas, lenguaje de la naturaleza, que, según la tradición cristiana, habla de Dios. La revelación del milagro está enfatizada por la repetición de Numen. Ahora bien, no se trata de que el poeta explique simplemente la causa del fenómeno tal y como podría hacer de tener una información privilegiada. Los datos de que dispone el hablante no difieren de los nuestros. Se trata de la capacidad de percibir la realidad. De ahí que el lenguaje adopte una perspectiva onomasiológica y de ahí también la diferencia en el uso del lenguaje figurado de un dístico a otro. Pero en realidad la relación de significación entre las dos partes del texto tiene un carácter elusivo, pues en lugar de explicar direc-

\footnotetext{
${ }^{37}$ Otro aspecto de la conexión lympha / nympha que puede resultar quizá interesante en este contexto es visible en los derivados lymphatus y lymphaticus, términos del lenguaje técnico, calcos una vez más del griego, que se basan en último extremo en la perdurable superstición -conservada aún en época moderna-referente a la locura que embarga a quien logra ver a las ninfas. Festo señala que quienes ven a las ninfas enloquecen para siempre (P.F. 107.17): lymphae dictae sunt a nymphis. Vulgo autem memoriae proditum est, quicumque speciem quandam e fonte, $i$. e. effigiem nymphae uiderint, furendi non fecisse finem. Pero cuando en el epigrama latino el universo mitológico se encuentre con el religioso el efecto será el contrario.
} 
tamente el significado del signo el poeta recurre a una metáfora. De este modo, la relación de significación se invertirá en cierto modo. Se establece así una relación entre dos signos. La metáfora que aparece en el último verso tiene por referente la transformación del agua en vino de la que se nos habla en el primero, y su función es precisamente hacer perceptible el símbolo que el milagro supone.

La personificación metafórica enlaza con el ámbito temático del banquete nupcial, pues el pudor evocado de la mujer en presencia de su amado casa bien con el escenario del banquete nupcial. El enrojecimiento del agua (lympha / nympha) recuerda claramente el tema del enamoramiento súbito y el encuentro de los enamorados. El uidit, et erubuit del verso final corresponde claramente al ut uidi, ut perii clásico. De este modo la transformación del agua en vino se convierte en una epifanía de lo femenino. El vino es la esencia del banquete, su alegría. Es el amor el que origina la metamorfosis. El banquete simboliza, por tanto, el matrimonio: un matrimonio sin amor sería como un banquete sin vino y sin alegría. Pero el vino del banquete matrimonial no es otro que la transformación del agua: el amor, el ingrediente esencial del matrimonio, como el vino lo es del banquete, debe ser puro, como lo es en el reino de la naturaleza el agua, y para ello debe basarse en la fraternidad y en el amor hacia Dios.

\title{
9.3. EL EPIGRAMA EN EL CONTEXTO DE LA POESÍA DE CRASHAW
}

Crashaw ha vuelto a tratar el tema de las bodas de Caná de forma muy parecida en otros pasajes de su obra. Es lo que ocurre en la traducción en verso que realizó este autor de un pasaje del Christus patiens de Hugo Grotius (Williams 1972, p.201):

\author{
What would they more? th' ave scene when at my nod \\ Great Natures selfe hath shrunke and spoke mee god. \\ Drinke fayling there where I a guest did shine \\ The water blush'd, and started into wine. \\ Full of high sparkeling vigour: taught by mee \\ A sweet inebriated extasy. \\ And streight of all this approbation gate, \\ Good wine in all poynts. but the easy rate.
}

Se trata del monólogo inicial de Cristo en la tragedia de Grotius (vv. 36-39). Pero el texto latino es muy diferente (1845, p.140):

\section{Fidei quid ultra restat? ad nutus meos \\ Natura rerum cessit et fassa est Deum. \\ Undae liquentis ebrios potus bibit \\ Galilaea pubes...}

La comparación de los dos textos con el epigrama sobre las bodas de Caná resulta sumamente interesante. En el texto de Grotius no hay rastro del tema del rubor. Hay, eso sí, una divinidad que se confiesa superada por el milagro, pero no es una ninfa, sino la propia naturaleza personificada. El vino se nos presenta de forma mucho más 
clara como portador de éxtasis y alegría (ebrios potus, se dice en el texto de Grotius). Otro aspecto interesante que está presente tanto en el texto de Grotius como en la traducción de Crashaw es el énfasis que en el monólogo de Cristo tiene la falta de respuesta a sus milagros por parte de los hombres, que, a pesar de todo, siguen sin tener fe en él. Este tema del monólogo enlaza claramente con la forma en que el epigrama está dramatizado, dirigido a las personas que presencian el banquete incitándoles a ver el milagro que revela la naturaleza divina de Cristo ${ }^{38}$.

En el monólogo, el milagro del agua transformada en vino está estrechamente relacionado con el de la multiplicación de los panes, a propósito del cual ambos autores muestran el contraste entre la alegría del banquete y el ascetismo del propio Cristo. El asombro de Ceres, que se confiesa superada por el milagro, corresponde al de la ninfa en el epigrama sobre las bodas y también al de la Naturaleza en la traducción de Grotius. Del mismo modo que nympha podía entenderse allí metonímicamente por agua, Ceres puede interpretarse, por otra parte, como metonimia por el pan. Resulta evidente la relación de estos textos con el tópico de la divinidad pagana que se asombra ante las novedades que se producen en algún ámbito relacionado con su esfera simbólica, del que nos hemos ocupado anteriormente. Otro aspecto interesante de este epigrama es, finalmente, la identificación eucarística de Cristo con el pan, enfatizada por la agudeza final ${ }^{39}$. El propio Cristo como vino es también tema común en la poesía latina de Crashaw. Así puede verse en el epigrama sobre la curación del hidrópico (Luc. 14. Hydropicus sanatur): Quippe in uina iterum Christus (puto) transtulit undas; / et nunc iste suis ebrius est ab aquis (vv. 3-4) ${ }^{40}$.

La ambigüedad del vino como símbolo puede observarse en el otro epigrama que el autor consagró al tema de la transformación del agua en vino (Williams 1972, p.305, Joann. 2, Ad Christum, de aqua in uinum uersa):

Signa tuis tuus hostis habet contraria signis:

In uinum tristes tu mihi uertis aquas.

Ille autem e uino lacrymas et iurgia ducens

Vina iterum in tristes (hei mihi!) mutat aquas.

\footnotetext{
${ }^{38}$ La misma insistencia en la falta de fe se encuentra en otro de los epigramas de Crashaw (Joann. 12.37. Cum tot signa edidisset, non credebant in eum) cuyo verso final concluye: Miraculum, qui non credidit, ipse fuit $(1634, \mathrm{p} .12)$.

${ }^{39}$ El tema de este milagro fue tratado por Crashaw en otro de sus epigramas sagrados (Joann. 6. Quinque panes ad quinque hominum millia (1634, p.4; 1670, p.3; Williams 1972, p.331), que insiste en la identificación de Cristo con el propio pan con que se alimentan los comensales. Denique quid restat? Pascitur ipse cibus (v. 4). El mismo énfasis se da en una de las variaciones sobre el tema cuyo dístico final afirma: Tunc pane hoc Christi recta satur (hospes) abibis, / panem ipsum Christum si magis esurias (Williams 1972, p.331). Y la misma conclusión se encuentra en otro de los epigramas del autor (Luc. 15.2. Murmurabant Pharisaei, dicentes, Recipit peccatores et comedit cum illis (1634, p.50; 1670, p.40; Williams 1972, p.351), que concluye (vv.3-4): Istis cum Christus conuiua adjungitur, istis / o non conuiua est Christus, at ipse cibus («Cuando Cristo come en compañia de tales gentes, no es un simple comensal, él mismo es la propia comida»).

${ }^{40}$ En otra variación sobre el mismo tema Cristo se identifica con el agua (Luc. 14.4. Hydropicus sanatus, Christum iam sitiens, Williams 1972, p.351), que concluye con los siguientes versos (vv.3-4): Foelix o, et mortem poterit qui temnere morbus! / Cui uitae ex ipso fonte sititur aqua! («iFeliz enfermedad que podrá despreciar la propia muerte! Tiene sed del agua que proviene de la propia fuente de la vida»).
} 
«Tiene el enemigo milagros propios, contrarios a los tuyos: tú me transformas las tristes aguas en vino; él, por su parte, extrayendo lágrimas y pendencias del vino, transmuta de nuevo el vino en tristes aguas».

El pecado, que transforma el placer en el dolor y que destila del gozo de la vida las lágrimas del arrepentimiento se presenta como lo inverso del milagro.

Como puede verse, el poema de Crashaw sobre el milagro de la conversión del agua en vino pone de manifiesto una clara conexión con temas y motivos reiterados en los epigramas sacros del autor, que es preciso tomar en cuenta a la hora de interpretar el texto.

\section{CONCLUSIONES: EL EPIGRAMA DE CRASHAW Y LA POESÍA NEO- LATINA}

Nuestra indagación a través de la poesía neolatina nos ha permitido extraer algunas conclusiones. En primer lugar hemos puesto de manifiesto la existencia de un tipo de cierre poético, ligado a una serie de motivos poéticos y a una constelación simbólica. Todos estos contextos resultan -creemos- interesantes a la hora de comprender el famoso poema de Crashaw, de modo que nuestros resultados pueden ser ahora aplicados a situar al texto en su contexto literario e histórico.

El cierre del tipo uidit et erubuit va unido generalmente a lo que hemos denominado una ficción conceptual; es decir, una ficción poética, basada en la ambigüedad a que da lugar siempre el lenguaje figurado y que sirve de vehículo a un concepto.

El tipo más simple de ficción de esta clase puede considerarse como una variante del tópico del sobrepujamiento. Una divinidad -o cualquier otro personaje relacionado-, perteneciente al pasado, especialmente al mundo clásico, la mitología y sus héroes, percibe un objeto que puede considerarse como una superación de dicho pasado y expresa su admiración, ya se trate de un doble del propio personaje del pasado o de algo relacionado con su esfera de acción. Este tipo de cierre puede considerarse como una alternativa a aquellos otros en que la figura representante del pasado cierra el texto con un breve discurso, que actúa como agudeza final -intradiegéticadel texto.

La conclusión subraya en estos casos la imposibilidad de hablar. En cambio, en otras ocasiones la ficción concluye con una metamorfosis, como en el resto de los tipos de ficción conceptual de los que nos hemos ocupado. En tales casos el rechazo de la palabra, característico de esta forma de cierre, da lugar a que los objetos se expresen mediante otra clase de lenguaje, a través de los signos.

Este tipo de contexto es similar precisamente al que encontramos en el texto de Grotius y en la traducción correspondiente de Crashaw. Natura rerum cessit et fassa est Deum se dice en el texto de Grotius, mientras que en la adaptación de Crashaw la frase se convierte en Great Natures selfe hath shrunke and spoke mee god. La Naturaleza se confiesa vencida y reconoce a Dios en Cristo. En el tipo de ficciones del que hablamos la Naturaleza es protagonista habitual en cuanto opuesta al arte o al es- 
píritu. El milagro sobrepasa las leyes de la naturaleza. Papel similar hace Ceres en el epigrama que hemos citado sobre el milagro de los panes. El signo deja paso al símbolo. Sin embargo, en el epigrama sacro la ninfa supone unas implicaciones de las que carece la personificación de la naturaleza.

Parece innecesario señalar las similitudes entre el epigrama de R. Crashaw y algunos de los epigramas que desarrollan el tema de la metamorfosis de la rosa. Cabría considerar el epigrama del autor inglés como una especie de versión a lo divino del tema. Tales semejanzas son fruto sin duda simplemente de los hábitos originados en el cultivo de una poesía basada en el concepto y en lo emblemático.

En los poemas sobre el origen de la rosa de Sabeo y Lernout, la ficción mitológica desempeña un doble papel; por una parte, el mito constituye el argumento del texto; por otra, el final, aunque puede situarse en el marco mitológico general, actúa también como equivalente de las ficciones conceptuales anteriormente citadas. El contraste entre el plano religioso y el mitológico, que el poema de Crashaw implica, corresponde al doble papel de la mitología en los poemas de Sabeo y Lernout, contraste que se redobla intertextualmente a través de la relación con el tema mítico del origen de la rosa. En ambos casos los seres naturales (rosa / agua) reconocen a la divinidad (deam flores sensere, dice el texto de Lernout y el de Crashaw nympha pudica deum uidit) y la reacción es la misma: el rubor. La diferencia radica sólo en que el tema de la metamorfosis de la rosa se ha conformado según el tópico del instrumento cómplice inocente del crimen. Al mismo tiempo, connotativamente la relación intertextual, intencionada o no, con el tema de la rosa, símbolo de feminidad, refuerza las implicaciones de la personificación del agua como ninfa dentro del contexto temático relativo al matrimonio.

En la poesía religiosa y moralizante de la época este tipo de cierre aparece ligado a la temática del martirio y a motivos como el del instrumento culpable involuntario de un crimen o al de la compasión de los instrumentos insensibles en contraste con la crueldad humana. La imposibilidad de la palabra va unida en este caso a su superación a través del símbolo. La ceguera de los hombres, incluso ante el milagro, contrasta con el poder simbólico de la realidad. En el epigrama de Crashaw se insiste en la ceguera humana ante la realidad sobrenatural, y el hablante urge a los asistentes al banquete a reconocer la presencia de la divinidad. A pesar del milagro, la humanidad permanece insensible a lo divino. Los objetos nos hablan de esa realidad superior al mundo, pero su simbolismo es ambiguo y se presta a interpretaciones diferentes. El color rosa se asocia al rubor, pero también a la pasión amorosa. El propio vino es un símbolo ambiguo, pues, por una parte, representa el goce de la vida $\mathrm{y}$, por otra, es símbolo del pecado como fruto del placer. Es sólo la poderosa alquimia de lo espiritual y de la fe la que hace que el hombre, rescatado de lo material, pueda alcanzar el auténtico placer, identificado con el propio Cristo. Esa condición ambigua es inherente a lo material y a lo humano y sólo se supera con el poder transformador del espíritu.

Los textos de los que nos hemos ocupado en este trabajo constituyen un claro reflejo de dos épocas y de dos sensibilidades literarias distintas. Por una parte, podemos ver un tipo de poesía que apela al mundo de los sentidos - tanto en lo que se 
refiere a la forma como al contenido- y que encuentra sus modelos poéticos en los epigramas griegos de la Antología, en la poesía anacreóntica y en Catulo. Este tipo de poesía es característica del siglo XVI, aunque dará lugar a una serie de tradiciones que permanecerán vivas a lo largo del XVII y del XVIII. De otra parte, encontramos una poesía basada en el ingenio, que triunfa en el XVII y que toma como modelo a Marcial ${ }^{41}$.

Los epigramas sacros y moralizantes del XVII, guardan estrecha relación con la literatura emblemática. El epigrama sacro glosa sistemáticamente las escenas del Antiguo y del Nuevo Testamento, o -en el caso de las obras católicas- las vidas de los santos. En una obra como los Lemmata nouo-antiqua de Cabilliau el entero universo natural y los episodios de toda la historia humana son sistemáticamente catalogados e interpretados desde un punto de vista moralizante ${ }^{42}$. En este tipo de poesía el universo sensual está acentuado hasta la exasperación, pero como trampa para los sentidos, como señuelo que aparta de la auténtica realidad. La poesía religiosa, sin dejar de ser campo abonado para el conflicto ideológico, se convierte en estos casos en una forma de meditación, en una especie de ejercicio espiritual.

Ambas sensibilidades poéticas pueden, por lo demás, conjugarse, como ocurre en la poesía a lo divino, plasmada en epigramas o elegías similares a los que encontramos en la Magdalena de Cabilliau o en los Pia desideria de Herman Hugo, donde la tradición anacreóntica o alejandrina se combina con la poesía emblemática, un tipo de poesía que en ocasiones alcanza una indudable altura poética, pero que corre el peligro de caer en una excesiva artificiosidad, que perjudica el sentimiento de lo sublime que los temas implican.

${ }^{41}$ No es difícil encontrar en la poesía religiosa de Crashaw módulos formales que remiten inequívocamente a Marcial. Así, cuando concluye uno de sus epigramas (Matth. 11. 25, In seculi sapientes) con el siguiente verso Simplicius poteris scilicet esse miser (v. 8), aunque no corresponde literalmente a ningún verso concreto de Marcial, este tipo de agudeza sólo es posible con el precedente de Marcial. Cf. Mart. 3.54.2: multo simplicius, Galla, negare potes.

${ }^{42}$ Cabilliau dedica toda una sección de su obra al desarrollo a ratione reddita, similar al del epigrama de Crashaw, por el que se explica la causa de un rasgo determinado de un objeto natural. En varios de ellos encontramos un cierre del mismo tipo. Así, en Unde rubor Corallo (1614, p.299) el coral, símbolo de pureza, enrojece púdicamente, al ser tocado por los pescadores: Ut tetigi incanas Neptuni germina baccas: / Par ostro intinxit tacta coralla rubor. / Nereidum et Nerei tam pura monilia credo / piscantum obscoenas erubuisse manus; en el titulado Unde pomo rubor. Ad hominem (1614, p.302) la manzana explica que su rubor se debe a su intervención en el pecado original: Erubui, it nocuo conscius ore pudor (v. 4). El titulado Cur botrus purpurascit (1614, p.303) concluye (v. 4): Stirpe notha uidit gignier; erubuit. En el titulado Cur rosa purpurascit (1614, p.305) el rojo de la rosa se justifica por la fugacidad de la flor: Auolo praeda noto. Dic pudor. Erubui (v. 4). En el poema dedicado a la anémona (Cur anemone sine odore rubeat, 1614, p.306) la propia flor afirma: Sol animam adspirat, roseoque figurat amoenas / Flore genas; cur non et mihi floris odor? / Pando sinum; Zephyri nusquam halitus. ite querelae. / Pars bona floris abest. o pudor! erubui. La anémona nace de la sangre de Adonis, lo que la hace similar a la rosa. Pero es también símbolo de lo efímero, flor del viento, que la arranca con facilidad. En este caso representa el alma, mientras que el viento es símbolo del espíritu y el color rojo indica aquí de nuevo culpabilidad. 


\section{REFERENCIAS BIBLIOGRÁFICAS}

Alois, P. (1635), Centuriae Epigramatum R.P. Petri Alois S.I., Lugduni, sumptibus C. du Four.

Alois, P. (1646), Petri Alois Neapolitani S.I. Epigrammatum centuriae sex, Neapoli, sumptibus I. Pierii.

Angeriano, G. (1582), Erotopaegnion, en Poetae tres elegantissimi emendati et aucti, Parisiis, apud D. Duvallium.

Aquino, C. (1701), Caroli de Aquino S.I. carminum tomus I, Romae, ex tipographia A. de Rubeis.

Asso DEL Río, I. DE (1786), Clariorum Aragonensium Monumenta in lucem prolata opera et studio Ignatii de Asso del Rí, Amstelaedami, apud haeredes C. Sommer et socios.

Barnard, F.P. (1922), A Fardel of Epigrams. Done into English by F.P. Barnard, Londres, Oxford University Press.

Bidermann, J. (1620), Iacobi Bidermani S.I. Epigrammatum libri tres, Coloniae Agrippinae, apud I. Kinckium; 1621, sumptibus S. Cramoisy, Parisiis; 1633, ed. quarta, Romae, formis heredum Facciotti; 1732, ed. octava, Venetiis, apud L. Basilium.

CABILliaU, B. (1614), Lemmata nouo-antiqua pancarpia ex natura, historia, moribus, in gratiam studiosae iuuentutis tetrastichis illigata, Ypris Flandorum, apud F. Bellettum.

Cabilliau, B. (1620), Balduini Cabillavi Yprensis S.I. Epigrammata selecta, Antuerpiae, apud B. Moretum, et viduam I. Moreti, - Io. Meursium.

Cabilliau, B. (1625), Magdalena, Antuerpiae, apud B. Moretum, et viduam I. Moreti, - Io. Meursium.

CABIlliau, B. y Malapert, CH. (1634), Bernardi Bauhusi et Balduini Cabillaui S.I. Epigrammata, Caroli Malapertii Poemata, Antuerpiae, ex officina Plantiniana B. Moreti.

Carmina Illustrium Poetarum Italorum (1720-1722), Florentiae, apud Cajetanum Tartinium (vol. VII, 1720, vol. IX, 1722).

Carmina quinque Hetruscorum (1562), Carmina quinque Hetruscorum poetarum, nunc primum in lucem edita, Florentiae, apud Juntas.

Conti, N. (1568), Mythologia, Venetiis.

Crashaw, R. (1634), Epigrammatum sacrorum liber, Cantabrigiae, ex Academiae celeberrimae typographeo.

CRASHAw, R. (1670), Richardi Crashawi poemata et epigrammata quae scripsit Latina et Graeca, editio secunda auctior et emendatior, Cantabrigiae, ex officina J. Hayes.

Crashaw, R. (1682), Epigrammata Sacra Selecta, cum Anglica Versione / Sacred Epigrams Englished, Londres, printed for J. Barksdale.

FigueroA, F. DE (1989), Poesía, M. López Suárez (ed.), Madrid, Cátedra.

ForCADEL, É. (1554), Stephani Forcatuli Iureconsulti Epigrammata, Lugduni, apud I. Tornaesium et G. Gazeium.

Galluzzi, T. (1616), Tarquinii Gallutii Sabini S.J. Carminum libri tres, Ingolstadii, per Elisabetham Angermariam viduam; 1619, Parisiis, apud S. Chappelet.

Grotius, H. (1845), Christus patiens, en Tragoediae selectae Latinorum recentiorum, Monachii, typis G. Weiss.

GrUter, J. (1608), Delitiae CC. Italorum poetarum hujus superiorisque aeui illustrium, Collectore Ranutio Ghero. 
Gruter, J. (1609), Delitiae C. Poetarum Gallorum huius superiorisque aeui, Collectore Ranutio Ghero.

GuInigi, V. (1627), Vincentii Guinisii Lucensis Poesis, Romae, apud F. Corbellettum; 1633, Antuerpiae, apud C. Cnobbaert; 1639, Parisiis, apud I. Camusat.

GuINIGI, V. (1637), Vincentii Guinisii Lucensis S.I. Poesis heroica, elegiaca, lyrica, epigrammatica aucta et recensita; item dramatica, nunc primum in luce, edita, Antuerpiae, ex officina Plantiniana B. Moreti.

HeARn, L. (1904), Kwaidan: Stories and Studies of Strange Things, Houghton Mifflin Company, Boston - New York. Trad. esp. 1962 ${ }^{3}$, Kwaidan, Madrid, Espasa Calpe.

Herbert, G. (1892), The Poetical Works of George Herbert, A.B. Grosart, ed., Londres, G. Bell and sons.

HERRICK, R. (1869), Hesperides: the poems and other remains of Robert Herrick, William Carew Hazlitt (ed.), I, Londres, John Russell Smith.

HILl, A. (1753), The Works of the Late Aaron Hill: Consisting of Letters on various Subjects, and of Original Poems, Moral and Facetious, III, Londres.

Hugo, V. (1885), Oeuvres complètes de Victor Hugo I, París, J. Hetzel - A. Quantin.

INTERIÁn DE AYALA, J. (1729), Humaniores atque amoeniores ad Musas excursus siue opuscula poetica, Matriti, Convento de la Merced.

Interián de Ayala, J. (1730), Pictor Christianus eruditus, Matriti, Convento de la Merced; 1782, El pintor christiano y erudito, I, Madrid.

KETTEN, J.M. VON DER (1699), Apelles symbolicus, exhibens seriem amplissimam symbolorum, poetisque, oratoribus ac uerbi Dei praedicatoribus conceptus subministrans uarios, II, Amstelaedami - Gedani, apud Janssonio-Waesbergios.

LAurens, P. (1975), Musae reduces. Anthologie de la poésie latine dans l'Europe de la Renaissance, Leiden, E.J. Brill.

LERNOUT, J. (1614), Jani Lernutii Initia, basia, ocelli et alia poëmata... ab ipso auctore publicata, Lugduni Batavorum, apud L. Elzevirium.

Maclean, C.D. (1880), Latin and Greek Verse Translations, Londres, Kegan Paul - Company. Picinelli, F. (1669), Mondo simbolico ampliato, Milán, nella stampa di F. Vigone.

Picinelli, F. (1681), Mundus Symbolicus, Coloniae Agrippinae, sumptibus H. Demen.

Poliziano, A. (1602), Angeli Politiani centuria prima, en Fax artium liberalium, hoc est, Thesaurus Criticus, Ianus Gruterus (ed.), I, Francofurti, sumtibus Ionae Rhodii.

Posthius, J. (1595), Parergorum poeticorum pars prima [Heidelberg], ex typographeio H. Commelini. Pozuelo Calero, B. (1994), «Poemas introductorios del licenciado Pacheco y de Benito Arias Montano a la Coena Romana de Pedro Vélez de Guevara», Humanistica Lovaniensia, 43, pp. 369-384.

Rollenhagen, G. (1606), Gabrielis Rollenhagii Magdaeburgensis Saxonis Iuuenilia, Magdaeburgi, impensis A. Kirchneri.

Ruiz SÁNCHEZ, M. (2004-2005), «La teoría de la bipartición del epigrama desde Scaligero hasta nuestros días. Consideraciones para un enfoque pragmático del género», Archivum 54-55, pp. 163-210.

SABEO, F. (1556), Epigrammatum Fausti Sabaei Brixiani libri V, Romae, apud V. et A. Doricos.

Silos, G. (1650), Musa canicularis siue iconum poeticarum libri III, Romae, typis heredum F. Corbelletti; 1652, Parisiis, apud P. Lamy, 1655, Parisiis, apud C. Thiboust, 1658, Parisiis, apud G. Marcher. 
Smith, S. (1856), Wit and Wisdom of the Rev. Sydney Smith, New York, Redfield.

TAssi, F. (ed.) (1829), Vita di Benvenuto Cellini orefice e scultore fiorentino, III, Florencia, presso Giuglielmo Piatti.

Tesauro, E. (1637), Reuerendi patris Emanuelis Thesauri S.I. Caesares, et eiusdem uaria carmina. Quibus accesserunt Nobilissimorum Orientis et Occidentis Pontificum elogia, et uaria opera poetica, Oxonii, impensis G. Weeb.

Williams, G.W. (1972), The Complete Poetry of R. Crashaw, New York, New York University Press. 